\title{
Why can we detect lianas from space?
}

Marco D. Visser ${ }^{1,2,}{ }^{*}$, Matteo Detto ${ }^{1}$, Félicien Meunier ${ }^{3,4}$, Jin Wu ${ }^{5}$, Jane Foster ${ }^{6}$, David C. Marvin ${ }^{7}$, Boris Bongalov $^{8}$, Matheus Henrique Nunes ${ }^{8,9}$, David Coomes ${ }^{8,10}$, Hans Verbeeck ${ }^{3}$, J. Antonio Guzmán $Q^{11}$, Arturo Sanchez-Azofeifa ${ }^{11}$, Chris J. Chandler ${ }^{12}$, Geertje M.F van der Heijden ${ }^{12}$, Doreen S. Boyd ${ }^{12}$, Giles M. Foody $^{12}$, Mark E.J.Cutler ${ }^{13}$, Eben N. Broadbent ${ }^{14}$, Shawn S. Serbin ${ }^{15}$, Stefan Schnitzer ${ }^{16}$, M. Elizabeth Rodríguez-Ronderos ${ }^{17}$ and Steve Pacala ${ }^{1}$

1. Department of Ecology and Evolutionary Biology, Princeton University, Princeton, NJ.

2. Institute of Environmental Sciences, Leiden University, Einsteinweg 2, 2333 CC Leiden, The Netherlands

3. Computational and Applied Vegetation Ecology, Department of Environment, Ghent University, Ghent, Belgium

4. Department of Earth and Environment, Boston University, Boston, USA

5. University of Hong Kong, Hong Kong.

6. Rubenstein School of Environment and Natural Resources, University of Vermont, Burlington, VT, USA

7. Salo Sciences, Inc., San Francisco, CA USA

8. Department of Plant Sciences, Forest Ecology and Conservation group, University of Cambridge, Cambridge, UK

9. Department of Geosciences and Geography, University of Helsinki, Helsinki, 00014, Finland,

10. Department of Plant Sciences, The Conservation Research Institute, University of Cambridge, Cambridge CB2 3QZ, UK.

11. Centre for Earth Observation Sciences (CEOS), Earth and Atmospheric Sciences Department, University of Alberta, Edmonton, Alberta, Canada T6M 2R7

12. School of Geography, University of Nottingham, University Park, Nottingham, United Kingdom

13. School of Social Sciences, University of Dundee, Dundee, United Kingdom

14. School of Forest Resources and Conservation, University of Florida, Gainesville, Florida, USA

15. Terrestrial Ecosystem Science \& Technology Group, Environmental Sciences Department, Brookhaven National Laboratory, Upton, NY 11973-5000, USA

16. Department of Biological Sciences, Marquette University, Milwaukee, WI 53201, USA

17. Department of Biological Sciences, National University of Singapore, Singapore

\footnotetext{
* corresponding author. $\underline{\text { m.d.visser@cml.leidenuniv.nl. }}$
} 


\begin{abstract}
Lianas are found in virtually all tropical forests and have strong impacts on the forest carbon cycle by slowing tree growth, increasing tree mortality and arresting forest succession. In a few local studies, ecologists have successfully differentiated lianas from trees using various remote sensing platforms including satellite images. This demonstrates a potential to use remote sensing to investigate liana dynamics at spatio-temporal scales beyond what is currently possible with ground-based inventory censuses. However, why do liana-infested tree crowns and forest stands display distinct spectral signals? And is the spectral signal of lianas only locally unique or consistent across continental and global scales? Unfortunately, we are not yet able to answer these questions, and without such an understanding the limitations and caveats of large-scale application of automated classifiers cannot be understood. Here, we tackle the questions of why we can detect lianas from airborne and spaceborne remote sensing platforms. We identify whether a distinct spectral distribution exists for lianas, when compared to their tree hosts, at the leaf, canopy and stand scales in the solar spectrum (400 to $2500 \mathrm{~nm}$ ). To do so, we compiled databases of (i) leaf reflectance spectra for over 4771 individual leaves of 539 species, (ii) finescale $\left(\sim 1 \mathrm{~m}^{2}\right)$ surface reflectance from 999 tree canopies characterized by different levels of liana infestation in Panama and Malaysia, and (iii) coarse-scale $\left(>100 \mathrm{~m}^{2}\right)$ surface reflectance from hundreds of hectares of heavily infested liana forest stands in French Guiana and Bolivia. Using these data, we find consistent spectral signal of liana-infested canopies across sites with a mean inter-site correlation of 89\% (range 74-94\%). However, as we find no consistent difference between liana and tree leaves, a distinct liana spectral signal appears to only manifests at the canopy and stand scales $\left(>1 \mathrm{~m}^{2}\right)$. To better understand this signal, we implement mechanistic radiative transfer models capable of modeling the vertically stratificatied non-linear mixing of spectral signals intrinsic to lianas infestation of forest canopies. Next, we inversely fit the models to observed spectral signals of lianas at all scales to identify key biochemical or biophysical processes. We then corroborate our model results with field data on liana leaf chemistry and canopy structural properties. Our results suggest that a liana-specific spectral distribution arises due to the combination of cheaply constructed leaves and efficient light interception. A model experiment revealed that the spectral distribution was most sensitive to lower leaf and water mass per unit area, affecting the absorption of NIR and SWIR radiation, and a more planophile (flatter) leaf angle distribution. Finally, we evaluate the theoretical discernibility of lianas from trees and how this varies with remote sensing platforms and resolution. We end by discussing the potential, limitations and risks of applying automated classifiers to detect lianas from remotely sensed data at large scales.
\end{abstract}




\section{Introduction}

Lianas are woody vines that act as structural parasites of trees. Lianas have a strong influence on forest dynamics (Visser et al., 2018b), decreasing tree growth and survival (Ingwell et al., 2010) and arresting forest succession (Tymen et al., 2016). Lianas are also abundant components of tropical forests (Dewalt et al., 2015) capable of affecting tree community composition (Muller-Landau and Visser, 2019) and severely reducing the terrestrial carbon sink (van der Heijden et al., 2015). Lianas are also reported to increase in abundance in many forests (Schnitzer and Bongers, 2011; Wright et al., 2015), raising concerns about the potential negative impact on carbon sequestration (Durán et al., 2013; Verbeeck and Kearsley, 2016). However, evidence of this increase is still limited, and the causes mostly unknown (Muller-Landau and Pacala, 2020; Schnitzer, 2015; Schnitzer et al., 2020). Remote sensing could provide a powerful tool to both quantify this trend on a broader range of spatiotemporal scales and elucidate the climatic and bio-geographical factors contributing to the liana proliferation.

Ecologists have applied a variety of remote sensing platforms to detect lianas at multiple sites, ranging from airborne (Chandler et al., 2021; Marvin et al., 2016) and drone multispectral sensors (Li et al., 2018; Waite et al., 2019) to satellite imagery (Foster et al., 2008; Tymen et al., 2016). This previous work suggests that lianas have distinct detectable spectral signals at the canopy and stand scales. However, investigation at the leaf scale shows that our ability to differentiate lianas and trees based on spectral properties might depend on forest type, with detectable differences in dry forests (Guzmán Q. and Sanchez-Azofeifa, 2021) but not in wet forests (Sánchez-Azofeifa et al., 2009). Similarly, liana leaves have several distinct chemical and structural properties compared to trees (Asner and Martin, 2012; Werden et al., 2018), however differences appear mediated by climatic factors, depending on temperature and being minimized in wetter forests (Asner and Martin, 2012; Medina-Vega et al., 2021a).

The mismatch among scales and the influence of climate raises doubts about the existence of a distinct global liana spectral signal and the applicability of remote sensing techniques to quantify liana abundances on large spatiotemporal scales. Without a distict signal, it may prove challenging to robustly apply automated classifying techniques across large spatial domains that differ in climate or floristic composition. Data-driven automated classifiers are powerful tools that capture complex non-linear relationships in training data (Bishop, 2006), but cannot generalize to out-of-sample scenarios when crucial relationships aren't represented in the training data (Devroye et al., 1996; Willard et al., 2020). It is possible that the connection between a spectral signal and ground condition appears strong at one location or time, but may be spuriously connected, or even fundamentally unconnected, with the phenomena of interest for the remote sensor (see for example Morton et al., 2014; Samanta et al., 2012; Soudani and François, 2014; Suits, 1971). If no consistent signal exists across sites, such a disconnect could also be true for the detection of lianas as well. The major challenge here is to collect trainingdata that is representative of all conditions though this may not be possible. This is particularly challenging in tropical forests because of the high biodiversity in both trees and lianas species and the presence of many confounders. For instance, many leaves and canopy traits are known to vary systematically among plant groups in relation to life history and leaf phenology, but differences can be 
small compared to the large variability across interspecific, intraspecific, phenotypic, and ontogenetic levels of natural vegetation (Castro-Esau et al., 2004; Detto and Xu, 2020; Kitajima et al., 2005; SánchezAzofeifa et al., 2009a; Werden et al., 2018; Wu et al., 2018; Zhang et al., 2006).

At a more fundamental level, however, pure data-driven automated classifiers do not elucidate our understanding of why lianas have a distinct spectral signal. An alternative approach to data-driven classifiers would be to build a mechanistic understanding of the liana spectral signal. This, in contrast, can provide the required insight needed to predict how the signal changes across regions, with climate or spatial scale (see e.g. Wu et al., 2018). Yet, such a physics-based approach would not be a universal remedy either as we expect trade-offs. In complex sitations pure data-driven classifiers tend to fail out of sample (Coveney et al., 2016; Karpatne et al., 2016) while physics-based mechanistic models, although unbiased out of sample, tend to have much lower precision (Féret et al., 2019; Gumiere et al., 2020). Interestingly, It is the combination of the two approaches that shows the most promise. In the field of machine learning there is a fast growing consensus that physical models and domain knowledge can constrain and improve automated classifiers (e.g. Raissi et al., 2019). Physics-informed classifiers have the ability to provide robust out of sample prediction with greatly improved precision (Willard et al., 2020). However, before the remote detection of lianas can benefit from physics-informed machine learning, we must start building a mechanistic understanding of the liana signal across various scales.

The first step towards building a mechanistic understanding of the liana spectral signal requires exploring and integrating the biochemical and biophysical components that structure the spectral signal of vegetation at different scales (e.g. Curran, 1989; Elvidge, 1990; Kokaly et al., 2009). Forest canopies are three-dimensional structures that variably reflect light depending on interactions between illumination conditions, viewing scale, and the chemical composition, density, and spatial arrangement of vegetative elements (Gates et al., 1965). Different biophysical traits variably affect canopy reflectance at different scales. For example, one of the challenges of detecting and quantifying liana infestation is that the leaves of the liana are vertically intertwined with these of the host tree. This integration of leaves produces a spectral mixture at the crown scale, which depends nonlinearly on the level of infestation and the spectral properties of the two endmembers.

Here we work to advance our understanding of liana optics. We provide a comprehensive exploration of the global liana spectral signal at the leaf, canopy and stand scales in the VIS, NIR and SWIR parts of the EM spectrum ( $400-2500 \mathrm{~nm}$ ). Our goal is to build an improved - mechanistic - understanding of the factors cause liana leaves and liana-rich canopies to have a distinct spectral signal from tree leaves and liana-free canopies. The challenge is to connect disparate traits, across multiple spatial scales, and predict how they influence remotely sensed spectra of liana and tree canopies. To do so, we rely on radiative transfer models to connect the various biochemical and biophysical traits of plant canopies to remotely sensed reflectance - and assess the relative contribution of each in determining a liana spectral distribution - if this exists.

The specific objectives of the work are to: 1) to verify if a characteristic liana spectral signal exists at the leaf, canopy and stand scale using various datasets assembled across the globe from a variety of spectral 
and remote sensing tools (table 1); 2) to explore the key biochemical and biophysical factors that are able of generating the liana spectral signal in theory by inversely fitting process-based radiative transfer models; 3 ) to test model inversion results with independent field data on these key traits; 4) to quantify the relative importance of each of these traits in determining the liana spectral signal; and 5) to evaluate the theoretical ability of spectral indices and automated classifiers to differentiate liana infestation at different scales using the simulated reflectance spectra.

\section{Methods}

Overview. We focus on liana reflectance in the $400-2500 \mathrm{~nm}$ parts of the EM spectrum, often termed the solar spectrum (e.g. Vermote et al., 1997; Yang et al., 2020), as this is where the bulk of the sun's energy is concentrated. We first compiled information on liana and non liana species reflectance from multiple sites, sensors and spatial scales. We then tested whether the distribution of liana reflectance was unique at the leaf-level by comparing lianas to several plant types (objective 1). Next, we quantified the similarity of the liana reflectance on larger scales across the globe, focusing specifically on case studies where tropical lianas and their host trees were successfully discriminated (objective 1; Chandler et al., 2021; Foster et al., 2008; Marvin et al., 2016; Tymen et al., 2016). Next, we inversely fit mechanistic radiative transfer models (RTMs) to leaf, canopy and stand scale data. We then quantify how lianas and their host trees differ in leaf biophysical, leaf chemical and canopy architectural properties using the model inversion results (objective 2) - and validated our model inversion results with direct ground measurements of the same traits (objective 3). To quantify the relative importance of each trait in generating the liana spectral distribution, we performed a series of iterative model experiments that quantified information loss in the liana signal by excluding each trait at the time (objective 4). Finally, we evaluated the theoretical ability of different platforms to discriminate between lianas and trees in a series of forward simulations (objective 5).

This paper integrates a large amount of data from multiple sites, sources and scales, and due to space and legibility concerns, we therefore placed details on field, data and lab protocols to the supplemental information

\subsection{Study sites, species and data.}

\section{Spectral datasets.}

To understand if a consistent global liana spectral signal exists across spatial scales and how this signal compares to other vegetation types, we assembled a comprehensive spectral dataset from 10 sites across the globe. Our data includes both well-known and novel datasets to the remote sensing community (Table 1, Fig 1). The data span three distinct spatial scales and include:

Leaf scale $\left(<<1 \mathrm{~m}^{2}\right.$ scale). We obtained leaf reflectance spectra from over 4774 leaves of 571 species. Our focus is primarily on tropical species, and our dataset includes 411 tropical tree species and 47 tropical liana species. However, to place liana leaf reflectance in a global context, we also include data on 36 temperate trees, 10 crops, 18 shrubs, and 25 herbaceous and grass species. In all datasets, leaf 
reflectance was measured in the $300 \mathrm{~nm}-2500 \mathrm{~nm}$ range ( $<2 \mathrm{~nm}$ step) with laboratory spectrophotometers or field spectroradiometers (Table 1 and Appendix S1). Crown scale (1-4 $\mathrm{m}^{2}$ scale). We quantified liana impacts on crown reflectance in two airborne hyperspectral campaigns. The first was collected in 2014 from Gigante Peninsula in central Panama, the second in 2016 in Danum Valley, Malaysia. At both sites, tree crowns were georeferenced, and the percent cover of liana infestation and leaf area index, were assessed based on ground surveys. In total, our dataset includes reflectance from 999 tree crowns (544 in Panama, 455 in Malaysia) with levels of crown infestation ranging from 0 to $100 \%$. Further details on the crown scale data, sites and instruments can be found in Appendix S1, Chandler et al., 2021; Marvin et al., 2016.

Stand scale ( $900 \mathrm{~m}^{2}$ scale). Two previous studies identified liana-arrested forest stands in Bolivia and French Guiana from satellite images. In both cases, reflectance data from adjacent low liana density forest was contrasted with heavily infested stands (Foster et al., 2008; Tymen et al., 2016). In French Guiana, heavily infested forest (hereafter "liana forest") was delineated from the liana-sparse forest (hereafter "forest") by Tymen et al (2016) using lidar (2007), aerial photography (2008) and field campaigns (2012). We obtained the same 30-m resolution Landsat Thematic Mapper image (L1TP) acquired on October 82006 used in the original study. In Bolivia, the liana forest was delineated and contrasted with random forest patches (hereafter also called "forest") by Foster et al (2008) using highresolution videography, and field surveys with Botanists. We obtained the same Hyperion imagery from NASA's EO- 1 satellite as the original study. The image includes 220 bands (at $0.1 \mu \mathrm{m}$ spectral resolution) across the shortwave portions of the full solar spectrum (400-2500 nm). Hyperion images have a comparable resolution to Landsat with a 30-m instantaneous field of view. The two images span 775.26 hectares of forest (40.5 in French Guiana, and 734.76 in Bolivia). Both images were georeferenced and surface reflectance corrected, and the Hyperion image was checked and corrected for the smile effect. We refer the reader to Tymen et al. 2016, Foster et al. 2008 and appendix S1 for additional details on the methods and sites.

\subsection{Leaf and canopy traits}

We combined published and novel field data on various leaf and canopy traits, including data on lianas and their host trees species from Panama and Malaysia.

Leaf biochemical and biophysical trait data. We obtained both leaf and species averaged measurements of leaf Chlorophyll $\left(C_{a b}, \mu \mathrm{g} / \mathrm{cm}^{2}\right)$, Carotenoids $\left(C_{a r}, \mu \mathrm{g} / \mathrm{cm}^{2}\right)$ and water content $\left(C_{w}, g / \mathrm{cm}^{2}\right)$, leaf thickness $(\mu \mathrm{m})$ and leaf mass area $\left(C_{m}, \mathrm{~g} / \mathrm{cm}^{2}\right)$. In all datasets, pigments contents were determined from leaf discs punched from fresh leaves immediately after sampling. Water content was determined by recording fresh weight before placing samples in a drying oven. Details on the sampling, extraction and quantification of leaf traits are given in more detail per dataset in appendix S1 for each dataset. For a subset of the data, individual leaf spectral reflectance and physically measured traits were matched for the same leaves (datasets 1,2, 5, and 10 in Table 1). In these cases, sampled leaf discs were extracted immediately after spectral measurements (appendix S1). The paired leaf data was used to benchmark 
leaf RTMs, as detailed below. In addition, we also obtained averaged values for lianas and trees of all traits from Sánchez-Azofeifa et al. (2009).

Leaf angles. We quantified the leaf angle distribution for canopies of 40 trees species (March 2013 \& January 2019) and 10 lianas species (January 2019) at two sites in the Republic of Panama, San Lorenzo and Barro Colorado Island (dataset 16). For trees, samples were taken from various heights in the canopy measured at $2 \mathrm{~m}$ height intervals using leveled-digital photography (Pisek et al., 2011; Ryu et al., 2010). A total of 415 digital images (223 in 2013, 192 in 2019) of leaves were taken at each location, where we ensured the camera was level before taking each picture. Pictures were taken from a canopy crane, a telecommunication tower, an eddy-covariance flux tower and in canopy gaps on the ground. We measured sun and shade leaves for trees, but only sun leaves for lianas, as lianas tend to lack shaded leaves (Avalos et al., 1999). Leaf angles were measured from digital pictures using imagel software (Rueden et al., 2017). Leaf angles were defined as the angular orientation of the leaf surface normal relative to the zenith (Ross, 1981). Whenever the leaves were compound, the angle from the petiole to the furthest leaf tip relative to the zenith was taken as the leaf angle. We also calculated the mean and standard deviation of the leaf angle distribution for each species, as well as for each growth form.

Plant area index (PAI). Differences between liana-free and infested canopy in plant area index (PAI) were estimated from LI-COR LAI2000 (dataset 15). LI-COR estimates of PAI capitalized on a liana removal experiment in central Panama. In short, $16(80 \times 80 \mathrm{~m})$ plots were established in 2008, in 8 plots all lianas all were cut with the remaining plots serving as controls. The vast majority of liana stems had fallen after 1 year, at which point the contribution of lianas to PAI could be estimated. Plant Area Index (PAI), the sum of leaf area index and wood area index, was measured in all plots 15 days prior to liana cutting, 6 weeks afterward, and then annually for $4 \mathrm{yr}$. A LI-COR LAl- 2000 plant canopy analyzer measured PAI in a uniform grid of 49 points within the central $60 \mathrm{~m} \times 60 \mathrm{~m}$ of each plot. The experiment is described in finer detail in Álvarez-Cansino et al. (2015) and van der Heijden et al. (2015), and the details regarding the LI-COR measurements given in Appendix S1, and Rodríguez-Ronderos et al. (2016).

\subsection{Radiative transfer theory}

To build a theoretical understanding of how the physical and chemical properties of liana leaves affect the spectral reflectance of forest canopies, we evaluated several analytically trackable radiative transfer models (RTMs). We implemented models from the PROSPECT and SAIL family of RTMs (Féret et al., 2017; Verhoef and Bach, 2003), which have been previously extensively validated and applied in reflectance modeling studies (e.g. Darvishzadeh et al., 2008; Shiklomanov et al., 2016; Si et al., 2012; Wu et al., 2018; Zhang et al., 2005). All models were programmed in $\mathrm{R}$, and optimized for speed following Visser et al. (2015) and refactored in C++ using Rcpp where needed (Eddelbuettel and François, 2011). Model code is available as the open source R-package ccrtm (coupled chain radiative transfer models; Visser, 2020). 
Prospect models. The PROSPECT family of leaf radiative transfer models are robust leaf RTMs with a long history of successful implementation in remote sensing (e.g. Jacquemoud et al., 2009; Shiklomanov et al., 2016). The models are exhaustively described elsewhere (e.g Jacquemoud and Ustin, 2019), though we provide a short description in Figure 2. PROSPECT models have two types of parameter inputs that describe leaf structural and biochemical traits (table 2). We evaluated PROSPECT 5, 5b and D (Feret et al., 2008; Féret et al., 2017) with respect to their ability to capture independently measured trait data. We then selected the model $(5,5 b$ or $D)$ that was able to reproduce the independent validation data most closely. To do so, we fitted each model to reflectance data from individual leaves where paired reflectance and trait data existed. Paired data were available for validation of several traits, which included: water mass per unit area $\left(C_{w}\right.$, or "equivalent water thickness"; datasets $\left.1,2,10\right)$, leaf mass area $\left(C_{m}\right.$, dry matter content; datasets $\left.1,2,10\right)$, chlorophyll content $\left(C_{a b}\right.$, datasets 1,2$)$ and carotenoids $\left(C_{a r}\right.$ datasets 1,2$)$ with their lab measured counterparts. We indirectly validated the leaf structure parameter $(\mathrm{N})$, with leaf thickness $(\mu \mathrm{m})$, as these parameters are correlated when the model is correctly fit (datasets $1,2,5,10)$. We lacked data to validate some parameters, including brown pigments $\left(C_{b r}\right)$ and anthocyanin content $\left(C_{a n}\right)$ for PROSPECT $5 b$ and $D$, respectively. Instead, we treat these as calibration parameters where their inclusion is supported if they improve the independent validation of the other parameters (see also Féret et al., 2017). Details on the fit procedure is given below, and all parameters and their units are given in Table 2.

Foursail models. The 4SAIL (or FOURSAIL) family of RTMs refers to a set of commonly used models that simulate bidirectional reflectance distribution functions within vegetation canopies (Jacquemoud et al., 2009). 4SAIL refers to "Scattering by Arbitrary Inclined Leaves", a model initially developed by Verhoef (1984, 1985), by extending Suits (1971)'s four-stream model. The four-stream model represents the scattering and absorption of upward, downward and two directional radiative fluxes with four linear differential equations in a 1-D canopy. Since its original formulation (Verhoef, 1984), the SAIL model has undergone multiple extensions including modelling the hotspot and heterogeneous canopies both horizontally (e.g. clumping) and vertically (Verhoef and Bach, 2007, 2003; Zhang et al., 2005, Fig 2). Most extensions are considered hybrid models that combine analytical and numerical elements (Kuusk, 2018; Verhoef and Bach, 2007).

The vast majority of liana species place leaves immediately above host leaves, forming a layer of leaves on top of their host crowns (Avalos et al., 1999; Stevens, 1987) with leaves found almost exclusively in the upper leaf layers (Medina-Vega et al., 2021b). A basal representation of a remotely sensed pixel of a liana infested crown is, therefore, one with two distinct and vertically separated leaf layers with liana leaves on top. This implies vertical mixing of vegetation types, which is known to be highly non-linear (Asner 1998), making any linear mixing of vegetation types inappropriate. We, therefore, chose to implement the 4SAIL2 model (Verhoef and Bach, 2007, 2003; Zhang et al., 2005) for its ability to represent vertically separated vegetation types while maintaining analytical tractability. In contrast to the simpler 4SAIL model, 4SAIL2 simulates the reflectance of two-component canopies, which may have two distinct vertically-separated canopy layers that can differ in leaf optics, optical thickness (LAI) and leaf inclination angles (see e.g. Braswell et al., 1996). As with the PROSPECT family of models, the SAIL 
model and its extensions have been exhaustively described elsewhere, though we provide a short description in Figure 2.

Coupled chain models: the PROSPECT and SAIL families of models can be coupled together in a chain, where the output from the former is used as input for the latter. The coupled models can represent all spatial scales considered here. Typically, the combined models of PROSPECT and SAIL are called PROSAIL (Jacquemoud et al., 2009), and we refer to our coupled model of PROSPECT with 4SAIL2 as PROSAIL2. The full PROSAIL2 model, which simulates the canopy and stand scale reflectance of liana infested forests, in its most completed form is given by:

$$
\begin{aligned}
& \hat{\tau}_{i}, \hat{\rho}_{i}=\operatorname{PROSPECT}\left(\lambda, N_{i}, C_{a b, i}, C_{a r, i}, C_{a n, i}, C_{b r, i}, C_{w, i}, C_{m, i}\right) \quad i=1,2 \\
& \hat{\rho}_{d}, \hat{\rho}_{h}=4 \operatorname{SAIL2}\left(\lambda, \hat{\tau}_{1}, \hat{\rho}_{1}, \hat{\tau}_{2}, \hat{\rho}_{2}, \mathrm{LAI}, \mathrm{L} \times \mathrm{f}_{2}, \Omega_{1}, \Omega_{2}, \mathrm{D}, \kappa, \mathrm{C}_{v} \zeta, \theta_{s}, \theta_{o}, \psi\right) \\
& \hat{\rho}=S\left(\lambda, \theta_{s}\right) \hat{\rho}_{d}+\left(1-S\left(\lambda, \theta_{s}\right)\right) \hat{\rho}_{s}
\end{aligned}
$$

Where $\tau_{1}, \tau_{2}, \hat{\rho}_{1}$ and $\hat{\rho}_{2}$ are the predicted leaf transmittance and reflectance for lianas (1) and trees (2) at wavelength $\lambda$, while $\hat{\rho}_{s}$ and $\hat{\rho}_{d}$ are the bidirectional reflectance and hemispherical directional reflectance for a canopy with infestation intensity $L$ (ranging between 0 and 1 ). The parameter $f_{2}$ divides the total leaf area between top and bottom layers (i.e., the fraction of LAl assigned to lianas is LAI $\mathbf{X}$ (1$f_{2}$ ), see Fig 2), and here we assumed that the optical thickness of the (top) liana layer $\left(1-f_{2}\right)$ is proportional to the liana infestation intensity $\left(L \times\left(1-f_{2}\right)\right)$ - this causes the canopy to revert to a single layer with one leaf type (trees) when infestation is zero, with the optical thickness of the top layer being $\left(1-f_{2}\right)$ when $L=1$. The final predicted reflectance off the target pixel $\hat{\rho}$ is then a function of the fraction diffuse light for wavelength $\lambda$ at solar zenith angle $\left(\theta_{s}\right)$ (following Danner et al., 2019; François et al., 2002). Details on all other parameters and their units are given in table 2.

\subsection{Inverse modelling of the liana signal}

The goal of spectral inverse modelling, or backward simulation of RTMs, is to estimate physical parameters values from observed reflectance data. Here, we used a Bayesian framework to robustly estimate the joint posterior distribution of all parameters (Shiklomanov et al., 2016). The posterior probability for a vector of RTM parameters $\boldsymbol{\varphi}$, and a vector $\mathbf{R}$ of observed reflectance values, is proportional to:

$$
P(\boldsymbol{\varphi}, \sigma \mid \mathbf{R}) \propto P(\boldsymbol{R} \mid \boldsymbol{\varphi}, \sigma) \mathrm{P}(\boldsymbol{\varphi}) \mathrm{P}(\sigma)
$$

Here $P(\boldsymbol{R} \mid \boldsymbol{\varphi}, \sigma)$ is the likelihood of observing reflectance vector $\mathbf{R}$, which is assumed to be normally distributed around the simulated reflectance predicted from parameter set $\varphi$ with a variance of $\sigma^{2}$. $\mathrm{P}(\boldsymbol{\varphi})$ and $\mathrm{P}(\sigma)$ are the prior probabilities of parameters $\boldsymbol{\varphi}$ and $\sigma$. Coupled chain models are particularly useful in a Bayesian framework, where models fit to data at one scale can become informative at another. Therefore, all priors in models fit to leaf-level reflectance were flat uniform priors, but at the canopy and stand scale all optical leaf parameters priors were set to normal distributions - which were informed by leaf-level fits (details in Appendix S2). 
We sampled the joint posterior distribution of each RTM with Monte-Carlo Markov Chain (MCMC) methods using the differential evolution adaptive metropolis algorithm (Vrugt and Ter Braak, 2011), implemented in the 'BayesianTools' R package (Hartig et al., 2019). In short, we initialized each inversion using randomly drawn parameter values from the prior distributions. For each inversion, we ran the algorithm for ten independent chains until convergence with a burn-in of 10,000 and 100,000 iterations for leaf scale and larger scales, respectively. MCMC convergence was determined based on a value of the Gelman-Rubin multivariate potential scale reduction factor of less than 1.035 as earlier explorative analyses revealed that this cutoff improved the fit (Gelman \& Rubin, 1992, Plummer et al., 2016). Convergence typically occurred after 10,000 to $10,000,000$ iterations, after burn-in, depending on model complexity. Each chain was run in parallel on a high-performance computing cluster, and we implemented a thinning interval of 10 , storing only every tenth iteration, as this ensured both 1) an accurate and representative sample of the joint posterior distribution and 2) saved memory usage tenfold. After applying the burn-in and thinning filter, credible intervals $(\mathrm{Cl})$ were calculated as the 2.5 and 97.5 percentile of the marginal distributions of each parameter - which are estimated by sampling from the joint posterior distribution using the MCMC.

We fit the PROSPECT 5, 5b and D models to all 4771 individual leaf reflectance data. At the canopy and stand scales, however, we only fit the PROSAIL2 model to datasets 11,12 and 14, because parameter uncertainty is sensitive to spectral resolution when inversely fitting RTMs (Shiklomanov et al., 2016). Therefore, we focus only on the hyperspectral data in our inverse fits, discarding the multispectral data from French Guiana (dataset 13). In the inversion process we specifically modelled each sensors spectral response functions. We conducted several model robustness checks including simulations to determine parameter identifiability and the effect of measurement error. These results are given in appendix S3.

\subsection{Spectral differences and the detection of the liana signal}

Measuring spectral differences. Comparison between spectral signals was quantified by the KullbackLeibler divergence; a measure of the difference between two probability distributions used in information theory (Kullback and Leibler, 1951). For a given spectral signal distributed $u(\rho, \lambda)$ of observing a reflectance value $\rho$ at wavelength $\lambda$ and reference distribution $v(\rho, \lambda)$ the Kullback-Leibler divergence was computed as:

$$
d_{k l}(u \mid v)=\int_{400}^{2500} \int_{0}^{1} u(\rho, \lambda) \log \frac{u(\rho, \lambda)}{v(\rho, \lambda)} d \lambda d r
$$

At the leaf level, we calculated $d_{k l}(u \mid v)$ for different plant groups, always using the observed spectral distribution of tropical liana leaves as the reference distribution $v(\rho, \lambda)$. Here $d_{k l}(u \mid v)$ can be interpreted to represent the loss of information when the liana spectral distribution is encoded with that from another plant group. The smaller the value, the more comparable the groups are. The expected Kullback-Leibler divergence between two identically distributed signals with equal means and variances 
is zero for all $\lambda$. Assuming normality, the spectral distribution can be estimated by calculating the mean and standard deviation at each wavelength. In this case the $d_{k l}(u \mid v)$ reduces to:

$$
d_{k l}(u \mid v)=\int_{400}^{2500} \log \left(\frac{\sigma(\lambda)_{v}}{\sigma(\lambda)_{u}}+\frac{\sigma(\lambda)_{u}^{2}+\left(\mu(\lambda)_{u}-\mu(\lambda)_{v}\right)^{2}}{2 \sigma(\lambda)_{v}^{2}}-\frac{1}{2}\right) d \lambda
$$

where $\mu(\lambda)_{u}, \mu(\lambda)_{v}, \sigma(\lambda)_{u}$ and $\sigma(\lambda)_{v}$ refer to the mean and standard deviations for the focal and reference distribution respectively. The wavelength of electromagnetic radiation is continuous, as we treat it above, however, note that in practice light is discretely measured in bands and this changes the formulation of Eq. 3 and 4 into a summation.

Estimates of variance are sensitive to sample size, and all plant groups differ in samples size, therefore in comparing $d_{k l}(u \mid v)$ across groups, we calculated $d_{k l}(u \mid v)$ with a bootstrapping approach that ensured equal sample size across all groups. We set bootstrap sample size to the smallest common sample size. The bootstrap samples across inter, intra and site specific variances in plant groups. Any detectable significant difference between plants groups suggest a robust distributional divergence despite inter/intra and spatio-tempral variance. We dropped any plant groups with less than 50 spectral samples from the analysis.

Model sensitivity experiment. Kullback-Leibler divergence can also quantify the loss or gain of information due to any single liana trait, by calculating $d_{k l}(u \mid v)$ between modelled spectra distributions that include or exclude one or more parameters. This provides a metric of the importance of various traits in generating the liana signal. Here, we represented distributions $u(\hat{\rho}, \lambda)$ and $v(\hat{\rho}, \lambda)$ as normal distributions with the predicted reflectance $\hat{\rho}$ giving the mean and $\sigma$ giving the variance (see Eq. 2 ). Here, we start with a model parameterized with estimated mean tree biophysical and biochemical leaf and canopy traits as focal distribution. We then iteratively change single parameters (additive effects), calculating the change in $d_{k l}(u \mid v)$ using the liana spectral distribution (with $\mathrm{L}=1$ ) as the reference distribution. This tests which single parameter produces the largest shift towards the liana spectral distribution (i.e. which parameter gives the largest information loss or gain). To gain an understanding of which parameters are most influential at different wavelengths, we also evaluated the Kullback-Leibler divergence at each wavelength separately - calculating only the integrand of Eq. 4. Secondly, we evaluate which combinations of two parameters (interactions) produce the largest shifts towards the liana signal - which informs on the parameter combinations that most strongly recreate the liana pattern.

The theoretical ability of classifiers to detect the liana signal. Kullback-Leibler divergence is also widely used in many machine-learning algorithms, as it is both a robust optimization criterion and provides a measure of the discernibility between feature and non-feature distributions (i.e. how detectable is the phenomenon of interest; Kosheleva and Kreinovich, 2017). Hence, $d_{k l}(u \mid v)$ provides a useful starting point to explore the theoretical ability of different platforms to discriminate between lianas and trees. In theory, sensors and spectral indices that sample at bands where the $d_{k l}(u \mid v)$ between trees and lianas is maximized will also maximize discernibility between groups. We, therefore, compare how well the spectral response function of a number of common multispectral remote sensing platforms (Landsat, Worldview 2, and Hyperion) maximized $d_{k l}(u \mid v)$. Here, we ignore atmospherical effects which will 
decrease the signal to noise ratio of most sensors (Yang et al., 2020), and results should be considered a first order approximation.

In addition, lianas are strongly spatially clustered at various scales (Ledo and Schnitzer, 2014), with lianas infestation ranging from a) incidental crown infestation (Marvin et al., 2016) to b) arrested succession (Schnitzer et al 2000), to c) many hectares of spatially aggregated liana forests (Tymen et al., 2016). We therefore explore how the scale of spatial aggregation interacts with the spatial resolution of a sensor in determining the expected $d_{k l}(u \mid v)$. Here we simulated $1000 \times 1000$-pixel hyperspectral image scenes as autocorrelated random fields, varying the scale and degree of autocorrelation for each of the three scenarios above $(\mathrm{a}-\mathrm{c})$. We then recalculated the expected $d_{k l}(u \mid v)$ between feature and non-feature, while gradually decreasing the spatial resolution from fine $(1 \times 1 \mathrm{~m})$ to coarse ( $250 \mathrm{~m} \times 250$ $\mathrm{m}$ ) by resampling each coarser scene using mean values from the higher resolution scene. This process was repeated 50 times for each scenario. The total number of feature pixels was kept approximately equal under all three scenarios. The simulation code is given in Appendix S5.

\section{Results}

The global liana signal at the leaf, canopy and stand scale.

The distribution of liana leaf reflectance, as measured from 725 leaves from 47 species, showed strong overlap among different species belonging to each of five broad plant groups (Fig 3 A). In our comparison (left most panels Fig 3B-C), we compare the bootstrapped Kullback-Leibler divergence $d_{k l}(u \mid v)$ at equal sample size between lianas and four other groups at each wavelength (Fig $3 \mathrm{~B}$ ) and overall (Fig 3C). The average divergence of lianas when bootstrapped among themselves compared to other groups, showed that the spectral distribution of lianas never departs from the confidence intervals of trees for any wavelength. Distinct distributional differences are found between lianas for shrubs and crops in the visual and shortwave infrared spectrum. Overall the spectral distribution of lianas was most similar on average with those of trees ( $\mathrm{Fig} 3 \mathrm{C}$ ), decreasing in average similarity with shrub species and showing the largest divergence with herbs and grasses; although here too, there was substantial overlap among all groups. The large overlap among groups in leaf reflectance reveals that, in general, no unique liana signal exists at the leaf scale.

The results at leaf scale contrast these at the canopy and stand scales, where the reflectance of the lianas-infested canopies consistently higher than the reflectance of lianas-free forests. This signal is remarkably similar across sites, platforms and wavelengths (Figure $1 \mathrm{~B} \& \mathrm{C}$ ). Comparisons of the difference signal ( $\mathbf{R}_{\text {lianas }}-\mathbf{R}_{\text {trees }}$; Fig 1B \& C lower panels) between sites show, on average, a correlation of $89 \%$ (range $74 \%$ to $99 \%$ ), when resampled to the bands of the Landsat 5TM signal (the platform used in French Guiana). When comparing only hyperspectral images obtained from Hyperion, at overlapping wavelengths, we observe a mean correlation of $96 \%$ for the hyperspectral difference signals (range 95\%$98 \%)$. This demonstrates that a unique spectral signal exists for liana reflectance at the canopy and stand scales, which is strikingly similar across the globe and detectable despite instrumental noise and sensor differences.

Modelling the liana spectral signal at the leaf, canopy and stand scales. We inversely fit PROSPECT5, PROSPECT5b and PROSPECTD to the spectral reflectance of 4771 individual leaves. All three models 
were able to reproduce the observed leaf signal to a large degree $\left(R^{2}>0.94\right.$; Appendix 56$)$, with PROSPECTD yielding the overall lowest error (see below for model validation). Inverse fits of the PROSAIL2 model, to canopy and stand scale data, approximated the spectral reflectance of heavily infested $(>50 \%$ cover) vs. lightly infested canopies $(<50 \%)$ from Bolivia, Malaysia and Panama to a very high degree $\left(R^{2}>0.98 ; \mathrm{Fig} 4 \mathrm{~A}-\mathrm{C}\right)$. The model was also capable of reproducing the difference between heavily and lightly infested canopies (inset plots in Fig 4 A-C). Predicted model differences explained the majority of variation, with $\mathrm{R}^{2}$ values ranging between 0.55 and 0.94 . Predicted reflectance was mostly unbiased when compared to the observed, however, the model tended to overestimate the difference in NIR reflectance especially when fit to the data in Panama (see 1:1 line in inset plot in Fig 4C). Model posteriors are given in appendix S7.

Model validation. Inverse fits with the PROSPECTD model, which are fit to leaf reflectance data, were the most successful in reproducing independently measured traits, and we therefore only discuss PROSPECTD in subsequent analysis at the canopy and stand scales. Benchmarks showed that the PROSPECT D model was able to estimate leaf trait parameters such as $C_{a r}, C_{a b}, C_{m}$ and $C_{w}$ in an accurate and unbiased way. Agreement between observed and predicted traits ranged between $R^{2}=0.4$ and $R^{2}=$ 0.73 (Appendix S8). This shows that the inclusion of the additional calibration parameters in PROSPECTD, $C_{b r}$ and $C_{a n}$, is worth it. We further found that the leaf structural parameter was indeed strongly related to leaf thickness $\left(R^{2}=0.54\right)$, indicating that the parameter was capturing meaningful physical variation among the leaves. The benchmarks for PROSPECT $5 \mathrm{~b}$ are given in Appendix $\mathrm{S} 8$.

Figure 5 shows the predicted difference between liana and trees from inverse fits of PROSAIL2 at the canopy and stand scales (black dots and whiskers) for all parameters that showed a nonoverlapping $\mathrm{Cl}$ for at least one site. The differences between lianas and trees in inversely estimated parameters tended to have a consistent pattern across all sites - but not all parameters had significant differences based 95\% credible intervals at all sites (Fig 5). Regarding leaf biophysical and chemical parameters, the models predict that lianas had more cheaply constructed leaves: often having thinner leaves and less photosynthetic pigment (Chlorophyll, and Carotenoids) per unit leaf area, and in all cases having lower dry mass and water mass per unit leaf area. Note that leaf water content (\%) is not the equivalent of $C_{w}\left(g / \mathrm{cm}^{2}\right)$, is calculated as $1-C_{m} /\left(C_{w}+C_{m}\right)$, and is in fact higher for lianas (77\% compared to $70 \%$ for trees on average). The predicted leaf absorption, reflectance, and transmission profiles are given in Appendix S9. Wherever independent leaf-level spectral data has been collected, inverse fits with PROSPECTD confirmed the PROSAIL2 predictions (see blue dots and whiskers in Fig 5). Canopy and stand scale parameters also differed between lianas and trees: liana leaf area was estimated to be 18 to $60 \%$ of tree LAI, while lianas were predicted to have flatter leaf angles for all sites.

Independently collected verification data, where available, underscored that the inverse fits with the PROSAIL2 model had captured the relevant differences between lianas and trees (red dots and whiskers in Fig 5). Lab measurements of leaf thickness, Chlorophyll and Carotenoids content per unit leaf area, less dry mass and water per unit area were all found to be lower on average for liana leaves at sites where they were available. Canopy and stand scale traits too showed agreement. Plant area index (PAI) as estimated from LI- COR dropped by $25 \%$ in plots where lianas were cut, indicating that trees contribute $\sim 75 \%$ of the LAI on average in infested canopies. Finally, leaf angles measured in the field confirmed that lianas on average have $\sim 24 \%$ flatter leaf angles (mean angle of $27.9^{\circ}$ vs $37.8^{\circ}$ ). 
What causes the liana signal? We conducted an iterative model experiment, where we started with the liana free canopy model for each site, and then iteratively permutated single or multiple traits, testing the effect of traits on $d_{k l}(u \mid v)$ - keeping the full liana model as a reference distribution. Parameter importance differed strongly dependent on which section of the solar spectrum we consider (Fig $6 \mathrm{~A}, \mathrm{C}$, E). Leaf angles $(\Omega)$, photosynthetic pigments content $\left(C_{a r}, C_{a b}\right)$ proved influential in the visual spectrum, with both flatter leaf angles and lower pigment content predicted to increase reflectance. In the nearinfrared, among the three most influential parameters leaf angles $(\Omega)$ was consistently the most important, followed by leaf mass area $\left(C_{m}\right)$ and leaf structure $(N)$ - though the latter two were more variable among sites. The importance of leaf water content $\left(C_{w}\right)$ increased with increasing wavelengths, dominating the signal at the tropical dry site Bolivia in the short-wave infrared. In general, both leaf angles $(\Omega)$, leaf mass area $\left(C_{m}\right)$ and leaf structure $(N)$ were relatively important. Our model experiments also revealed the single most influential traits overall (Fig $6 \mathrm{~B}, \mathrm{D}, \mathrm{F}$ ), being those that brought the modelled spectral distribution closest to that of lianas, were leaf water content $\left(C_{w}\right)$, leaf mass area $\left(C_{m}\right)$ and leaf angles $(\Omega)$. With leaf angle being consistently important across sites, and the relative importance of leaf water content and leaf mass area varied strongly between sites. The leaf structural parameter $(\mathrm{N})$ was also of considerable influence, though it tended to shift the distribution further away from the liana spectral distribution, to when the $\mathrm{N}$ value for trees was replaced with that for lianas.

Theoretical limits to the detection of liana. The expected KL-divergence between the spectral distribution of liana and trees maximizes in the NIR and SWIR bands. A number of multispectral spaceborne sensors sample these ranges (Fig $7 \mathrm{~A}$ ), and the more bands that fall within the optimal range, the greater the overall performance of the sensor should be in discriminating lianas from trees (Fig 7B). Sensor spatial resolution also interacts with the spatial aggregation of lianas (Fig 7C-E). Under a crown infestation scenario (liana pixel aggregation $350 \mathrm{~m}^{2}$ ), we found that the divergence between the feature distribution and background drops rapidly, faster than expected if the feature pixels were randomly distributed (black dashed line in Fig $7 \mathrm{C}$ ). Where the spatial aggregation was larger, resembling arrested forest succession $\left(2000 \mathrm{~m}^{2}\right)$, divergence dropped slower and roughly at the same pace as would be expected for random feature pixels (Fig 7D). Finally, when lianas are highly spatially aggregated across many hectares of forest $\left(\sim 30000 \mathrm{~m}^{2}\right)$, we see that the divergence drops slower than the random expectation.

\section{Discussion}

We provide evidence for a distinct liana spectral distribution when compared to trees at the canopy and stand scale (Fig 1, $4 \& 7$ ). A feature of the liana spectral distribution is that it can be generally characterized by higher albedo across the solar spectrum (Fig $1 \& 4$ ) and that it is most divergent from trees in the NIR and SWIR portions of the solar spectrum (Fig 7). The existence of a distinct spectral distribution across four globally distributed sites provides a basis for extending work on lianas towards pantropical scales, and raises new questions on the evolution of lianas and the consequences of liana infestation for forest energy budgets. In addition, the traits we identify as drivers of the liana spectral distribution are not necessarily unique to lianas, and thus, a real danger exists for confounding with other phenomena. In this final section, we shortly touch on all the above points by 1) giving a hypothesis 
on why lianas have evolved a similar spectral distribution compared to trees across the globe, 2) elaborating on the consequences of liana infestation for forest energy budgets, 3) providing a set of recommendations for the robust detection of lianas.

\subsection{The mechanisms behind the liana spectral signal}

Our analysis shows that a general distinct spectral distribution for lianas, distinct across sites and species, is absent at the leaf scale $\left(\ll<1 \mathrm{~m}^{2} ; \mathrm{Fig} 3\right)$ and only manifests itself at the canopy and stand scales $(\geq 1 \mathrm{~m} 2$; Fig $1 \& 4$ ). This is supported by previous work that show that the liana spectral distribution and traits are site and species specific (Sánchez-Azofeifa et al., 2009; Asner and Martin, 2012; Medina-Vega et al., 2021a). The absence of a clear signal at the leaf scale suggests canopy traits, or interactions between leaf and canopy traits, drive the distinct distribution observed by multiple patforms here (figure $1 \& 4$ ). This is supported by our mechanistic radiative transfer model inversions. Our inversion at the leaf scale suggest that lianas - on average - tend to have more cheaply constructed leaves with flatter leaf angles when compared to trees (Fig 5, 6; Asner and Martin, 2012). The differences in leaf traits between lianas and trees should not lead to any consistent differences between liana and tree leaves in reflectance (Fig S7), but should result in lower absorption and increased transmission across the solar spectrum in all evaluated sites (Fig S6). It is probable, therefore, that a distinct liana reflectance distribution arises due to two components: 1) a direct component due to a higher projected leaf area, which will lead to more energy reflected at equal reflectance, and 2) a multiple scattering component that arises due to larger leaf transmission and lower absorption, an effect similar to what is hypothesized to cause canopy greening (Wu et al., 2018).

Building on our models, and some additional basic math, we can generate a set of theoretical expectation on how the two components help generate the observed liana distribution. The first component is a direct effect of projected leaf area. As mentioned before, lianas retain on average $24 \%$ flatter leaf angles $\left(27.9^{\circ}\right.$ vs $\left.37.8^{\circ}\right)$, which should result in roughly a $11 \%$ increase in projected leaf area as seen from a polar angle and a proportional increase in the reflected energy. The second component, a multiple scattering component, takes place because liana leaves tend to have lower absorption on average (Fig S7). A simple approximation shows that light energy should decay at a slower rate in interaction with liana leaves (Appendix S8). This means that more energy is scattered, including more in the observer's direction, and this results in an increased contribution of reflectance when integrated across the canopy. In addition, multiple scattering also explains the regions where the liana spectral distribution is maximally divergent from trees (Fig 7). The importance of the first component should be relatively fixed across the spectrum (Fig 6) - as the projected leaf area does not change. The importance of multiple scattering to the liana signal, however, should peak whenever transmission is maximized.

This occurs in the SWIR and NIR parts of the spectrum (Fig S6), which indeed corresponds to the point of maximal discernibility of the liana distribution (Fig 7), and where leaf traits appear the most influential in our sensitivity analysis (Fig 6). Both components involve multiple leaves (i.e. canopies): the entire projected leaf area and interactions between leaves. Therefore, we hypothesize that the distinct liana signal arrises due to interactions between multiple leaves. Which explains why the signal only manifesting itself at the canopy scale (Fig 1 \& 4; Chandler et al 2021, Waite et al 2020, Foster et al 2006) 
and the apparent lack of a consistent signal when only leaf reflectance is considered at sub cm scale in our work and elsewhere (Sánchez-Azofeifa et al., 2009).

\subsection{Study limitations}

The main result from model inversion was backed up by independent measurements in the field. Separate measurements on leaf reflectance, and in situ measurements of leaf traits and angles, both confirmed that lianas tend to have relatively flatter leaf angles and more cheaply constructed leaves with less dry matter and pigments. However, the model's predictions were not always perfectly in line with ground truth data. On an absolute scale, ground measurements of mean leaf angles were lower compared to the mean leaf angles predicted by PROSAIL2 (Appendix S8). One explanation for this is that PROSAIL2 greatly simplifies the structural heterogeneity of tropical forest. In addition, we do not consider the effect of leaf clustering on stems and branches in our field campaign, while the PROSAIL2 result is more likely to reflect the integrated angles of leaves clustered on stems and branches. In Malaysia, PROSAIL2 was also found to overpredict parameters $C_{w}$ and $C_{m}$, this contrasts with our results for Panama where observations on leaf traits matched. The discrepancy could be caused by the fact that leaf traits were averaged over multiple sites in Panama, while for Malaysia we only have leaf trait measurements for lianas from a single site, Sepilok, roughly $100 \mathrm{~km}$ away from where canopy reflectance measurements were made in Danum Valley (table 1). Sites are known to differ in their trait averages (Asner and Martin, 2012; Sánchez-Azofeifa et al., 2009a), and this could explain the observed inconsistency.

\subsection{Ecological consequences of the liana spectral signal}

Forest albedo is a measure of the incident energy reflected back to the atmosphere, and it is directly related to the energy absorbed, the energy budgets and the understorey light conditions in forested ecosystems (e.g. Monson \& Baldocchi, 2014). Here we show that the spectral distribution of lianas is characterized by higher albedo (Fig 1 \& 4), and it follows that this can potentially have important consequences for both forest energy budgets and understory light conditions. Given that tropical forests are generally considered light-limited and multiple studies report that liana abundance is on the rise in the Neotropics (Schnitzer and Bongers, 2011; Wright et al., 2015), how plausible is it that liana proliferation could have impacts beyond what is currently known?

Meunier et al. (2021) integrated the liana optical properties into the ED2 dynamic vegetation model, and suggested several consequences. First, the energy reflected back to the atmosphere was predicted to increase by $11.7-17.1 \%$ across the PAR and IR spectrum driven again by the combined effects of liana leaf traits and larger canopy-level projected leaf area. This corresponded to a reduction of energy absorbed of $3.6 \mathrm{~W} \mathrm{~m}^{-2}$ when lianas traits were accounted for. As more energy is reflected back in the simulations, fewer photons reached the ground resulting in darker understories (by up to $50 \%$ ), which also resulted in slightly cooler soils (on average $-0.5^{\circ} \mathrm{C}$ in the topsoil over a five year simulation. Such results emphasize that the liana spectral signal has consequences beyond its application to remote sensing: it directly impacts forest functioning. We believe this shows that there is a direct and urgent need for empirical validation of these model predictions in future research. Fundamental long-term changes could be underway in for forested ecosystems that are experiencing increasing liana prevalence. 


\subsection{Robust detection of lianas.}

Our simulations on the theoretical limits of liana detection show three key findings (Fig 7). First, spectral distributional differences between lianas and trees are not equal across the spectrum and not all sensor platforms sample the solar spectrum at bands optimal bands for the detection of lianas. Many platforms only have a single band at an optimal position (Fig 7A). Second, the detection of liana infestation where spatial aggregation occurs only on small scales, such as within tree crowns, will require high spatial resolution as the signal decays rapidly (Fig $7 \mathrm{C}$ ). The detection and mapping of crown infestation is therefore something which is unlikely to be achieved robustly with moderate scale platforms (e.g. 10 $30 \mathrm{~m}$ resolution). Moderate and coarse scale platforms, however, are predicted to be more successful in detecting large swaths of liana infested areas - as here the signal is expected to decay far less rapidly (Fig 7E). Third, the liana spectral distribution also decays non-linearly with the degree of crown infestation (colored lines in Fig 7C-E) - this non-linearity is expected due to the vertical mixing of liana and tree canopy layers. Our three findings tend to agree with the achievements of previous studies. To date, studies that used moderate resolution platforms, such as Hyperion and Landsat, were successful in the detection of large areas of liana arrested succession (Foster et al., 2008; Tymen et al., 2016) but only where very high resolution hyperspectral images were available did studies successfully detected liana infestation in tree crowns and then only for severely infested crowns ( $>50 \%$, Chandler et al., 2021; Marvin et al., 2016). These insights and their agreement with previous work, shows that our analysis can be used to guide future remote work on lianas, and help match study goals with sensor choice.

Our characterization of the mechanisms behind the liana spectral distribution warns for the cautious application of classifiers as the signal may be confounded. A non-exhaustive list of confounders include:

i) Leaf phenology. Young and immature tree leaves tend to have a lower $C_{m}, C w$ pigment concentrations. The result is that young leaves are more transmissive, and this leads to a similar signal as lianas (see for instance Wu et al., 2018 and Hesketh \& Sánchez-Azofeifa 2012).

ii) Tree life history. Light demanding and pioneer tree species tend to have flatter leaf angles, as well as more cheaply constructed and thinner leaves.

iii) Topography and sun-sensor geometry. One possible confounder here is that areas sloped towards the sun will appear to have relative higher reflectance across the spectrum.

Each of the confounders above have unique aspects that may enable disentanglement. First, we expect shifts in leaf phenology will be seasonal while liana infestation should be a more permanent temporal signal. In dry forests, lianas tend to retain their leaves for longer, and such temporal disconnects between lianas and trees in phenology can help detection.

Second, the literature shows that light demanding trees species are seldomly infested with lianas (Clark and Clark, 1990; Visser et al., 2018a) and tend to have fewer leaf layers (Kitajima, 1994). This should make them discernable if structural information, from lidar or SAR, can be added to a classifier in combination with spectral data (e.g. as is done in physics-assisted machine learning, Rao et al., 2020). The combination of structure and spectral information is especially promising, as we expect strong structural changes due to liana infestation. For instance, lianas substantially alter the wood area index of infested canopies (Sánchez-Azofeifa et al., 2009b). The confounding effects of topography and sun-sensor geometry may be minimized by careful preprocessing of scenes with digital elevation models 
that match the resolution of the images. However, as our list of confounders is not complete, and many more potential factors can cause local increases in albedo in a fashion that may be similar to liana infestation. It follows that the application of automated classifiers across large spatial scales should be done cautiously, with at the very least a validation that shows robustness to these and other confounders. We note that additional caution should be taken when applying sensor platforms with only a single band at an optimal position for liana discrimination (Fig 7A), as a multitude of other factors can cause confounding of the liana signal in a single band.

\subsection{Conclusions}

We show existence of a distinct and consistent spectral distribution for lianas detected by both air and spaceborne sensors. This distribution appears to only arise at the canopy scale, and our models suggest that this is foremost the result of lower light absorbtion and greater projected leaf areas which leads to an increased scattering of light (i.e. reflectance). If the distinct liana signal - detected here across only four but globally distributed sites - proves robust this would have important implications for future research. In essence, it would provide both the basis and the need to develop robust classifiers to help quantify liana abundance and proliferation and it's impacts on the terrestrial forest carbon budget. The need is illustrated by the observation that the liana spectral distribution is characterized by increased forest albedo compared to trees. This highlights that lianas may have a substantial impact on forest energy budgets and understory dynamics (Meunier et al. 2021). In turn, the successful application of radiative transfer models in this study, also provides a basis to develop physics-informed classifiers which could strengthen the robustness of liana detection algorithms. All in all, fertile ground exists for future research into the liana spectral signal, its robust detection from remote sensing platforms, and the ecological consequences of liana prolifiration. 


\section{Tables and figures}

Figure 1. Spectral datasets used in this study to quantify the spectral signal of lianas compared to trees. Panel A shows the location and type of every spectral dataset included in this study. Dataset numbers correspond to numbering in Table 1, and color denotes type and scale (green, red and blue for leaf, canopy and stand). Panels $B$ and $C$ provide the liana spectral signal detected by airborne and spaceborne sensors for our focal sites in Bolivia, French Guiana, Malaysian and Panama. Top rows show the distinct surface reflectance signal displayed by forest or liana poor tree crowns $\left(R_{\text {tree }}\right)$ and liana forests or heavily infested liana crowns $\left(R_{\text {liana }}\right)$ at each location. The bottom rows show the average difference between $R_{\text {lianas }}$ and $R_{\text {trees. }}$ Intercomparisons of the difference signal $\left(R_{\text {lianas }}-R_{\text {trees }}\right)$ between sites shows a correlation of on average $89 \%$ (range $74 \%$ to $99 \%$ ), and excluding the multispectral Landsat 5 tm signal from French Guiana, we observe a mean intercorrelation of $96 \%$ for the hyperspectral signals (range 95\%-98\%). This intercorrelations suggest that a distinct liana signal exists, when compared to trees, and that this signal is similar across the globe and sensor platforms at the canopy and stand scales.

Figure 2. Conceptual illustration of the coupled radiative transfer models used in this study. Radiative transfer at the leaf stage is modelled by the PROSPECT family of models. Here, light absorption $(\alpha)$, transmittance $(\tau)$ and reflectance $(\rho)$ of individual leaves are represented as semi-transparent stacked plates with $\mathrm{N}-1$ airspaces (for $\mathrm{N}$ plates). Plates represent the number of compact layers in a leaf with the average number of air/cell walls interfaces within the mesophyll given by $N$. The dynamics of $\alpha, \tau$ and $\rho$ are then described by the generalized plate model (Allen 1970, Breece \& Hilmes 1971, Stokes 1962), and each plate's wavelength-dependent transmissivity $(\mathrm{k}(\lambda))$. This, in turn, is calculated as a linear combination of empirical absorption coefficients and area-based concentrations of major components of leaf biochemistry $\left(C_{w}\right.$, water; $C_{m}$, dry matter; $C_{a b}$, chlorophyll; $C_{a r}$, carotenoids; $C_{a n}$, Anthocyanin; $C_{b r}$, brown pigments). Leaf chemical constituents are treated as homogeneous within and among the stacked plates, though, though in reality these are heterogeneous with regards to ventral vs dorsal sides, or in distinct parts of leaf cells (cell walls vs interior; Gates 1960). Despite these, and other, assumptions PROSPECT models are capable of accurately capturing physical traits of leaves from their reflection signatures. The FOURSAIL family of models simulate canopy or stand level bi-directional reflectance from a set of differential equations representing 2 direct and 2 hemispherical radiance steams: direct specular flux (irradiance), reflectance in the observer direction (radiance in the direction of the sensor), and scatter in downward and upward directions (diffuse radiance). The FOURSAIL2 model divides a canopy into two distinct vertically separated layers, which are two horizontally infinite layers with randomly distributed flat plates (leaves), that are isotropic in their azimuth direction. The model can take the predicted leaf $\alpha, \rho$ and $\tau$ values directly from PROSPECT models as input and there can be two distinct particle types, with unique $\tau$ and $r$, which can be completely separated by layer or fully mixed depending on the canopy dislocation parameter (D). Here D is set to 1 , conform the empirical observations that liana leaves are almost exclusively placed on top of host leaves. Each layer has an optical depth defined by sensor-sun geometry $\left(\theta_{s}, \theta_{0}, \psi\right)$, which influences the relative length of radiance fluxes, and the angular projection of leaf area - which is a function of the mean leaf angle in each layers $\left(\Omega_{1}, \Omega_{2}\right)$ and the total leaf area index (LAI). LAI, in turn, is distributed as $\left(1-f_{2}\right) \times$ LAl and $f_{2} \times$ LAI 
for the top and bottom layer respectively. The canopy is bounded below by a soil layer, which has a unique wavelength dependent reflectance that depends on a soil moisture parameter $(\omega)$. The model considers an angular dependency which occurs when the observer viewing zenith and solar zenith angle are equal. At this point, the probability of solar flux traveling to and from any point in the canopy are not independent, resulting in an increased reflectance called the hotspot. The peak intensity of the hotspot is a function of the canopy coarseness, estimated as leaf width over canopy height, and expressed by the hotspot parameter $(\mathrm{k})$. The model includes a crown cover fraction $\left(\mathrm{C}_{\mathrm{v}}\right)$ and crown shape parameter (द) that regulate, in concert with viewing geometry, the fraction of visible and shaded bare soil (Rosema et al., 1992; Verhoef and Bach, 2007). However, bare soil is virtually never visible as vegetation cover in all modelled tropical forests is uniformly high (>99\%). Therefore, we simplified the model by setting $C_{v}$ to 1. This eliminates the influence of crown shape parameter $(\zeta)$ on reflectance, and both $\zeta$ and $C_{v}$ are therefore ignored throughout the text. Drawings by MDV.

Figure 3. Leaf reflectance compared across plants shows large variation, and substantial overlap, with no clear differences emerging in leaf reflectance signals. The panel in column A, show the measured reflectance in the solar spectrum (wavelengths between 400 to $2500 \mathrm{~nm}$ ) of various plant species, grouped in broad categories. Here, the black dashed line indicates the mean reflectance for lianas, while the colored envelopes represent the $2.5 \%$ to $97.5 \%$ percentile interval of measured reflectance for each group. The groups are, from top to bottom, crops species, herbs and grasses, shrubs, trees and lianas (see also color legend in column C). The panel in column B, show the distribution of Kullback-Leiber divergence scores at each wavelength for each group compared to the liana distribution (bottom Panel in A). Here, Kullback-Leiber divergence scores were bootstrapped at equal sample size between groups and, for lianas, within the group. Panel in column $\mathrm{C}$, show the average total divergence across all wavelengths and include the bootstrapped $95 \%$ confidence intervals (dots and whiskers).

Figure 4. Model predictions for high and low levels of lianas coverage compared to their observed reflectance from airborne and satellite hyperspectral signals. Dotted lines and colored envelopes give mean and inter quartile range (IRQ) respectively. Model fits were uniformly high, as measured by the coefficient of determination $\left(R^{2}>0.98\right)$. Inset plots show model predictions of the differences in the signal between high and low liana coverage, which all compared well with the observed difference $\left(R^{2}=\right.$ $0.443,0.927,0.966$, respectively for Bolivia, Malaysia and Panama). We note that mechanistic models such as PROSPECT and FOURSAIL have many free parameters, which provide a lot of flexibility that can easily result in very high fits. Therefore, Figure 5 , provides a superior test of model fit, where we compare fit parameters with their independently measured counterparts.

Figure 5. Inversely estimated and independently observed leaf and canopy traits for liana covered forest canopies compared to liana free (tree) canopies. Inversely estimated traits from full canopy models (black), are compared to inverse estimates from leaf models on leaf optical data (blue), and to independently measured traits (red) - whenever the latter two were available for lianas and trees at a site. All traits are displayed as a percentage of the average tree traits, which enables comparisons on a single scale. Absolute trait values, and comparisons to ground truth data, are given in appendices (X-Y). Solid dots and whiskers denote mean and $95 \%$ credible intervals. Parameters that never showed a significant difference between groups in any sites were excluded from Figure 5 for clarity. All parameters and their posterior distributions are given in Appendix S7. 
Figure 6. Model experiment showing the relative importance of different traits in generating the liana signal. In all model experiments, the traits in the top layer were set to tree traits, and then iteratively replaced with liana traits either one by one (additive) or in pairs (interactive effects). At each interaction, the change in the KL-divergence score was calculated. Panels $A, C$, and $E$ give the relative absolute impact of changing a single trait in the top canopy layer at each wavelength. Panels $B, D$ and $F$ give the total impact of additive (darker colors) and interactive effects (lighter colors). Here, a positive impact refers to a change in the direction of the liana signal, while a negative impact refers to in a change away from the liana signal.

Figure 7. Theoretical ability of classifiers to discriminate lianas from their background as measured by the expected Kullback-Leiber divergence. The predicted Kullback -Leiber divergence across all wavelengths (A), as estimated from the models when liana infestation is $100 \%$. Here, the variance at each wavelength was estimated by sampling from the model posterior distribution. The spectral sampling regions for a number of remote sensing platforms are super imposed on the image, indicating whether the band samples lie in optimum locations for liana discrimination. Panel B shows the mean Kullback -Leiber divergence across all bands for each sensor as estimated from the information given in A. Panels $C-E$, show the simulated effects of sensor spatial resolution on the discernibility of lianas in relation to the spatial aggregation of lianas. Here, discernibility, is measured by the divergence between the spectral distribution of the feature (liana infestation) and the spectral distribution of the nonfeature. Panel columns C, D and E, each denote a scenario of spatial aggregation; crown scale infestation (C), forest gap arrestation (D) and liana forests (E). Examples of simulated scenes and their resampling are given in the top row, while the results of spatial scale on the Kullback-Leiber divergence are shown below. In each simulation the mean size of the cluster of lianas differs from 350,2000 to $30000 \mathrm{~m}^{2}$ in columns $A, B$ and $C$ respectively. These aggregation scales correspond to scales of infestation in various studies (A in Marvin et al 2016, and Chandler et al 2020, B in Schnitzer et al.,(2000) and C in Foster et al 2006 and Tymen et al 2016). Colormap corresponds to the infestation level of a pixel within a scene, which is related to the vertical optical thickness of lianas (left legend). The color of lines (right legend) corresponds to the feature of interest in the bottom row graphs. Grey vertical lines correspond to $1 \times 1$, $30 \times 30$ and $250 \times 250 \mathrm{~m}$ resolution, while the black dashed line gives the expected decline in the relative divergence if feature pixels were randomly distributed. All scenarios had an approximately equal number of feature pixels. 


\section{References}

Álvarez-Cansino, L., Schnitzer, S.A., Reid, J.P., Powers, J.S., 2015. Liana competition with tropical trees varies seasonally but not with tree species identity. Ecology 96, 39-45. https://doi.org/10.1890/141002.1

Asner, G.P., 1998. Biophysical and biochemical sources of variability in canopy reflectance. Remote Sens. Environ. 64, 234-253. https://doi.org/10.1016/S0034-4257(98)00014-5

Asner, G.P., Martin, R.E., 2012. Contrasting leaf chemical traits in tropical lianas and trees: Implications for future forest composition. Ecol. Lett. 15, 1001-1007. https://doi.org/10.1111/j.14610248.2012.01821.x

Avalos, G., Mulkey, S., Kitajima, K., 1999. Leaf optical properties of trees and lianas in the outer canopy of a tropical dry forest. Biotropica 31, 517-520.

Bishop, C.M., 2006. Pattern Recognition and Machine Learning, Pattern Recognition. https://doi.org/10.1117/1.2819119

Braswell, B.H., Schimel, D.S., Privette, J.L., Moore, B., Emery, W.J., Sulzman, E.W., Hudak, A.T., 1996. Extracting ecological and biophysical information from AVHRR optical data: An integrated algorithm based on inverse modeling. J. Geophys. Res. Atmos. 101, 23335-23348. https://doi.org/10.1029/96jd02181

Castro-Esau, K.L., Sánchez-Azofeifa, G.A., Caelli, T., 2004. Discrimination of lianas and trees with leaflevel hyperspectral data. Remote Sens. Environ. 90, 353-372. https://doi.org/10.1016/J.RSE.2004.01.013

Chandler, C.J., Heijden, G.M.F. Van Der, Doreen, S., Waite, C.E., Cutler, M.E.J., Costa, H., Nilus, R., Foody, G.M., 2021. Remote sensing liana infestation in an aseasonal tropical forest: addressing mismatch in spatial units of analyses. J. Remote Sens. Conserv. https://doi.org/10.1002/rse2.197

Clark, D.B., Clark, D.A., 1990. Distribution and effects on tree growth of lianas and woody hemiepiphytes in a Costa Rican tropical wet forest. J. Trop. Ecol. 6, 321-331. https://doi.org/10.1017/S0266467400004570

Coveney, P. V., Dougherty, E.R., Highfield, R.R., 2016. Big data need big theory too. Philos. Trans. R. Soc. A Math. Phys. Eng. Sci. 374. https://doi.org/10.1098/RSTA.2016.0153

Danner, M., Berger, K., Wocher, M., Mauser, W., Hank, T., 2019. Fitted PROSAIL Parameterization of Leaf Inclinations, Water Content and Brown Pigment Content for Winter Wheat and Maize Canopies. Remote Sens. 11, 1150. https://doi.org/10.3390/rs11101150

Darvishzadeh, R., Skidmore, A., Schlerf, M., Atzberger, C., 2008. Inversion of a radiative transfer model for estimating vegetation LAI and chlorophyll in a heterogeneous grassland. Remote Sens. Environ. 112, 2592-2604. https://doi.org/10.1016/j.rse.2007.12.003

Detto, M., Xu, X., 2020. Optimal leaf life strategies determine $V_{c, \text { max }}$ dynamic during ontogeny. New Phytol. 228, 361-375. https://doi.org/10.1111/nph.16712

Devroye, L., Györfi, L., Lugosi, G., 1996. A Probabilistic Theory of Pattern Recognition, Stochastic Modelling and Applied Probability. Springer New York, New York, NY. https://doi.org/10.1007/9781-4612-0711-5

Dewalt, S.J., Schnitzer, S.A., Alves, L.F., Bongers, F., Burnham, R.J., Cai, Z., Carson, W.P., Chave, J., Chuyong, G.B., Costa, F.R.C., Ewango, C.E.N., Gallagher, R. V., Gerwing, J.J., Amezcua, E.G., Hart, T., Ibarra-Manríquez, G., Ickes, K., Kenfack, D., Letcher, S.G., Macía, M.J., Makana, J.R., Malizia, A., Martínez-Ramos, M., Mascaro, J., Muthumperumal, C., Muthuramkumar, S., Nogueira, A., Parren, M.P.E., Parthasarathy, N., Pérez-Salicrup, D.R., Putz, F.E., Romero-Saltos, H.G., Sridhar Reddy, M., Sainge, M.N., Thomas, D., Melis, J. Van, 2015. Biogeographical patterns of liana abundance and diversity, in: Ecology of Lianas. pp. 131-146. https://doi.org/10.1002/9781118392409.ch11

Durán, S.M., Gianoli, E., Duran, S.M., Gianoli, E., 2013. Carbon stocks in tropical forests decrease with liana density. Biol. Lett. 9, 20130301. https://doi.org/10.1098/rsbl.2013.0301 
Eddelbuettel, D., François, R., 2011. Rcpp: Seamless R and C++ integration. J. Stat. Softw. 40, 1-18.

Feret, J.B., François, C., Asner, G.P., Gitelson, A.A., Martin, R.E., Bidel, L.P.R., Ustin, S.L., le Maire, G., Jacquemoud, S., 2008. PROSPECT-4 and 5: Advances in the leaf optical properties model separating photosynthetic pigments. Remote Sens. Environ. 112, 3030-3043.

https://doi.org/10.1016/j.rse.2008.02.012

Féret, J.B., Gitelson, A.A., Noble, S.D., Jacquemoud, S., 2017. PROSPECT-D: Towards modeling leaf optical properties through a complete lifecycle. Remote Sens. Environ. 193, 204-215. https://doi.org/10.1016/j.rse.2017.03.004

Féret, J.B., le Maire, G., Jay, S., Berveiller, D., Bendoula, R., Hmimina, G., Cheraiet, A., Oliveira, J.C., Ponzoni, F.J., Solanki, T., de Boissieu, F., Chave, J., Nouvellon, Y., Porcar-Castell, A., Proisy, C., Soudani, K., Gastellu-Etchegorry, J.P., Lefèvre-Fonollosa, M.J., 2019. Estimating leaf mass per area and equivalent water thickness based on leaf optical properties: Potential and limitations of physical modeling and machine learning. Remote Sens. Environ. 231, 110959. https://doi.org/10.1016/J.RSE.2018.11.002

Foster, J.R., Townsend, P.A., Zganjar, C.E., 2008. Spatial and temporal patterns of gap dominance by lowcanopy lianas detected using EO-1 Hyperion and Landsat Thematic Mapper. Remote Sens. Environ. 112, 2104-2117. https://doi.org/10.1016/j.rse.2007.07.027

François, C., Ottlé, C., Olioso, A., Prévot, L., Bruguier, N., Ducros, Y., 2002. Conversion of 400-1100 nm vegetation albedo measurements into total shortwave broadband albedo using a canopy radiative transfer model. Agronomie 22, 611-618. https://doi.org/10.1051/agro:2002033

Gates, D.M., Keegan, H.J., Schleter, J.C., Weidner, V.R., 1965. Spectral Properties of Plants. Appl. Opt. 4, 11. https://doi.org/10.1364/ao.4.000011

Gumiere, S.J., Camporese, M., Botto, A., Lafond, J.A., Paniconi, C., Gallichand, J., Rousseau, A.N., 2020. Machine Learning vs. Physics-Based Modeling for Real-Time Irrigation Management. Front. Water 0, 8. https://doi.org/10.3389/FRWA.2020.00008

Guzmán Q., J.A., Sanchez-Azofeifa, G.A., 2021. Prediction of leaf traits of lianas and trees via the integration of wavelet spectra in the visible-near infrared and thermal infrared domains. Remote Sens. Environ. 259, 112406. https://doi.org/10.1016/J.RSE.2021.112406

Hartig, F., Minunno, F., Paul, S., Cameron, D., 2019. BayesianTools: General-Purpose MCMC and SMC Samplers and Tools for Bayesian Statistics. R Packag. version 0.1.7.

Ingwell, L.L., Wright, S.J., Becklund, K.K., Hubbell, S.P., Schnitzer, S.A., 2010. The impact of lianas on 10 years of tree growth and mortality on Barro Colorado Island, Panama. J. Ecol. 98, 879-887. https://doi.org/10.1111/j.1365-2745.2010.01676.x

Jacquemoud, S., Ustin, S.L., 2019. Leaf Optical Properties. Cambridge University Press, Cambridge.

Jacquemoud, S., Verhoef, W., Baret, F., Bacour, C., Zarco-Tejada, P.J., Asner, G.P., François, C., Ustin, S.L., 2009. PROSPECT + SAIL models: A review of use for vegetation characterization. Remote Sens. Environ. 113, S56-S66. https://doi.org/10.1016/j.rse.2008.01.026

Karpatne, A., Atluri, G., Faghmous, J., Steinbach, M., Banerjee, A., Ganguly, A., Shekhar, S., Samatova, N., Kumar, V., 2016. Theory-guided Data Science: A New Paradigm for Scientific Discovery from Data. IEEE Trans. Knowl. Data Eng. 29, 2318-2331. https://doi.org/10.1109/tkde.2017.2720168

Kitajima, K., 1994. Relative importance of photosynthetic traits and allocation patterns as correlates of seedling shade tolerance of 13 tropical trees. Oecologia 98, 419-428. https://doi.org/10.1007/BF00324232

Kitajima, K., Mulkey, S., Wright, S., 2005. Variation in crown light utilization characteristics among tropical canopy trees. Ann. Bot. 95, 535-547.

Kosheleva, O., Kreinovich, V., 2017. Why Deep Learning Methods Use KL Divergence Instead of Least Squares: A Possible Pedagogical Explanation Recommended Citation, Part of the Computer Sciences Commons Comments. 
Kullback, S., Leibler, R.A., 1951. On Information and Sufficiency. Ann. Math. Stat. 22, 79-86. https://doi.org/10.1214/aoms/1177729694

Kuusk, A., 2018. Canopy Radiative Transfer Modeling, in: Liang, S. (Ed.), Comprehensive Remote Sensing V. 3 Remote Sensing of Terrestrial Ecosystem. Elsvier, pp. 9-22. https://doi.org/10.1016/B978-012-409548-9.10534-2

Ledo, A., Schnitzer, S.A., 2014. Disturbance and clonal reproduction determine liana distribution and maintain liana diversity in a tropical forest. Ecology 95, 2169-2178. https://doi.org/10.1890/131775.1

Li, W., Campos-Vargas, C., Marzahn, P., Sanchez-Azofeifa, A., 2018. On the estimation of tree mortality and liana infestation using a deep self-encoding network. Int. J. Appl. Earth Obs. Geoinf. 73, 1-13. https://doi.org/10.1016/j.jag.2018.05.025

Marvin, D.C., Asner, G.P., Schnitzer, S.A., 2016. Liana canopy cover mapped throughout a tropical forest with high-fidelity imaging spectroscopy. Remote Sens. Environ. 176, 98-106. https://doi.org/10.1016/j.rse.2015.12.028

Medina-Vega, J.A., Bongers, F., Poorter, L., Schnitzer, S.A., Sterck, F.J., 2021a. Lianas have more acquisitive traits than trees in a dry but not in a wet forest. J. Ecol. 109, 2367-2384. https://doi.org/10.1111/1365-2745.13644

Medina-Vega, J.A., Bongers, F., Schnitzer, S.A., Sterck, F.J., 2021b. Lianas explore the forest canopy more effectively than trees under drier conditions. Funct. Ecol. 35, 318-329. https://doi.org/10.1111/1365-2435.13717

Meunier, F., Visser, M.D., Shiklomanov, A., Dietze, M.C., Antonio Guzmán, J.Q., Sanchez-Azofeifa, A., T De Deurwaerder, H.P., Krishna Moorthy, S.M., Schnitzer, S.A., Marvin, D.C., Longo, M., Chang, L., Broadbent, E.N., Almeyda Zambrano, A.M., Muller-Landau, H., Detto, M., Verbeeck, H., 2021. Liana optical traits increase tropical forest albedo and reduce ecosystem productivity. bioRxiv. https://doi.org/10.1101/2021.06.08.447067

Morton, D.C., Nagol, J., Carabajal, C.C., Rosette, J., Palace, M., Cook, B.D., Vermote, E.F., Harding, D.J., North, P.R.J., 2014. Amazon forests maintain consistent canopy structure and greenness during the dry season. Nature 506, 221-224. https://doi.org/10.1038/nature13006

Muller-Landau, H.C., Pacala, S.W., 2020. What Determines the Abundance of Lianas?, in: Dobson, A., Holt, B., Tilman, D. (Eds.), Unsolved Problems in Ecology. Princeton University Press, Princeton, NJ, pp. 239-264.

Muller-Landau, H.C., Visser, M.D., 2019. How do lianas and vines influence competitive differences and niche differences among tree species?? Concepts and a case study in a tropical forest. J. Ecol. 1469-1481. https://doi.org/10.1111/1365-2745.13119

Ollinger, S. V., 2011. Sources of variability in canopy reflectance and the convergent properties of plants. New Phytol. https://doi.org/10.1111/j.1469-8137.2010.03536.x

Pisek, J., Ryu, Y., Alikas, K., 2011. Estimating leaf inclination and G-function from leveled digital camera photography in broadleaf canopies. Trees - Struct. Funct. 25, 919-924. https://doi.org/10.1007/s00468-011-0566-6

Raissi, M., Perdikaris, P., Karniadakis, G.E., 2019. Physics-informed neural networks: A deep learning framework for solving forward and inverse problems involving nonlinear partial differential equations. J. Comput. Phys. 378, 686-707. https://doi.org/10.1016/J.JCP.2018.10.045

Rao, K., Williams, A.P., Flefil, J.F., Konings, A.G., 2020. SAR-enhanced mapping of live fuel moisture content. Remote Sens. Environ. 245, 111797. https://doi.org/10.1016/j.rse.2020.111797

Rodríguez-Ronderos, M.E., Bohrer, G., Sanchez-Azofeifa, A., Powers, J.S., Schnitzer, S.A., 2016. Contribution of lianas to plant area index and canopy structure in a Panamanian forest. Ecology 97, 3271-3277. https://doi.org/10.1002/ecy.1597

Rosema, A., Verhoef, W., Noorbergen, H., Borgesius, J.J., 1992. A new forest light interaction model in 
support of forest monitoring. Remote Sens. Environ. 42, 23-41. https://doi.org/10.1016/00344257(92)90065-R

Ross, J., 1981. The radiation regime and architecture of plant stands, The radiation regime and architecture of plant stands. Springer Netherlands, The Hague. https://doi.org/10.1007/978-94009-8647-3

Rueden, C.T., Schindelin, J., Hiner, M.C., DeZonia, B.E., Walter, A.E., Arena, E.T., Eliceiri, K.W., 2017. ImageJ2: ImageJ for the next generation of scientific image data. BMC Bioinformatics 18, 529. https://doi.org/10.1186/s12859-017-1934-z

Ryu, Y., Sonnentag, O., Nilson, T., Vargas, R., Kobayashi, H., Wenk, R., Baldocchi, D.D., 2010. How to quantify tree leaf area index in an open savanna ecosystem: A multi-instrument and multi-model approach. Agric. For. Meteorol. 150, 63-76. https://doi.org/10.1016/j.agrformet.2009.08.007

Samanta, A., Ganguly, S., Vermote, E., Nemani, R.R., Myneni, R.B., 2012. Why Is Remote Sensing of Amazon Forest Greenness So Challenging? Earth Interact. 16, 1-14. https://doi.org/10.1175/2012ei440.1

Sánchez-Azofeifa, G.A., Castro, K., Wright, S.J., Gamon, J., Kalacska, M., Rivard, B., Schnitzer, S.A., Feng, J.L., 2009a. Differences in leaf traits, leaf internal structure, and spectral reflectance between two communities of lianas and trees: Implications for remote sensing in tropical environments. Remote Sens. Environ. 113, 2076-2088. https://doi.org/10.1016/j.rse.2009.05.013

Sánchez-Azofeifa, G.A., Kalácska, M., Espírito-Santo, M.M. do, Fernandes, G.W., Schnitzer, S., 2009b. Tropical dry forest succession and the contribution of lianas to wood area index (WAI). For. Ecol. Manage. 258, 941-948. https://doi.org/10.1016/J.FORECO.2008.10.007

Schnitzer, S. a. S., Dalling, J.W.J., Carson, W.W.P., 2000. The impact of lianas on tree regeneration in tropical forest canopy gaps: Evidence for an alternative pathway of gap-phase regeneration. J. Ecol. 88, 655-666. https://doi.org/10.1046/j.1365-2745.2000.00489.x

Schnitzer, S.A., 2015. Increasing liana abundance in neotropical forests: causes and consequences, in: Schnitzer, S.A., Bongers, F., Burnham, R.J., Putz, F.E. (Eds.), Ecology of Lianas. John Wiley \& Sons, Chichester, UK, pp. 451-464.

Schnitzer, S.A., Bongers, F., 2011. Increasing liana abundance and biomass in tropical forests: Emerging patterns and putative mechanisms. Ecol. Lett. 14, 397-406. https://doi.org/10.1111/j.14610248.2011.01590.x

Schnitzer, S.A., Estrada-Villegas, S., Wright, S.J., 2020. The response of lianas to $20 \mathrm{yr}$ of nutrient addition in a Panamanian forest. Ecology 101. https://doi.org/10.1002/ecy.3190

Shiklomanov, A.N., Dietze, M.C., Viskari, T., Townsend, P.A., Serbin, S.P., 2016. Quantifying the influences of spectral resolution on uncertainty in leaf trait estimates through a Bayesian approach to RTM inversion. Remote Sens. Environ. 183, 226-238. https://doi.org/10.1016/j.rse.2016.05.023

Si, Y., Schlerf, M., Zurita-Milla, R., Skidmore, A., Wang, T., 2012. Mapping spatio-temporal variation of grassland quantity and quality using MERIS data and the PROSAIL model. Remote Sens. Environ. 121, 415-425. https://doi.org/10.1016/j.rse.2012.02.011

Soudani, K., François, C., 2014. Remote sensing: A green illusion. Nature. https://doi.org/10.1038/nature13052

Stevens, G.C., 1987. Lianas as structural parasites: the Bursera simaruba example. Ecology. https://doi.org/10.2307/1938806

Suits, G.H., 1971. The calculation of the directional reflectance of a vegetative canopy. Remote Sens. Environ. 2, 117-125. https://doi.org/10.1016/0034-4257(71)90085-X

Tymen, B., Réjoul-Méchain, M., Dalling, J.W., Fauset, S., Feldpausch, T.R., Norden, N., Phillips, O.L., Turner, B.L., Viers, J.J., Chave, J.J., Réjou-Méchain, M., Dalling, J.W., Fauset, S., Feldpausch, T.R., Norden, N., Phillips, O.L., Turner, B.L., Viers, J.J., Chave, J.J., 2016. Evidence for arrested succession in a liana-infested Amazonian forest. J. Ecol. 104, 149-159. https://doi.org/10.1111/1365- 


\subsection{4}

van der Heijden, G.M., Powers, J.S., Schnitzer, S.A., 2015. Lianas reduce carbon accumulation and storage in tropical forests. Proc. Natl. Acad. Sci. 112, 13267-13271.

Verbeeck, H., Kearsley, E., 2016. The importance of including lianas in global vegetationmodels. Proc. Natl. Acad. Sci. U. S. A. https://doi.org/10.1073/pnas.1521343113

Verhoef, W., 1984. Light scattering by leaf layers with application to canopy reflectance modeling: The SAIL model. Remote Sens. Environ. 16, 125-141. https://doi.org/10.1016/0034-4257(84)90057-9

Verhoef, W., Bach, H., 2007. Coupled soil-leaf-canopy and atmosphere radiative transfer modeling to simulate hyperspectral multi-angular surface reflectance and TOA radiance data. Remote Sens. Environ. 109, 166-182. https://doi.org/10.1016/j.rse.2006.12.013

Verhoef, W., Bach, H., 2003. Remote sensing data assimilation using coupled radiative transfer models. Phys. Chem. Earth 28, 3-13. https://doi.org/10.1016/S1474-7065(03)00003-2

Vermote, E.F., Tanré, D., Deuzé, J.L., Herman, M., Morcrette, J.J., 1997. Second simulation of the satellite signal in the solar spectrum, 6s: an overview. IEEE Trans. Geosci. Remote Sens. 35, 675-686. https://doi.org/10.1109/36.581987

Visser, M.D., 2020. ccrtm: Coupled Chain Radiative Transfer Models. https://cran.rproject.org/web/packages/ccrtm/index.html

Visser, M.D., Kroon, H. De, Muller-landau, H.C., Schnitzer, S.A., Jongejans, E., 2018a. A host - parasite model explains variation in liana infestation among co- - occurring tree species 2435-2445. https://doi.org/10.1111/1365-2745.12997

Visser, M.D., McMahon, S.M., Merow, C., Dixon, P.M., Record, S., Jongejans, E., 2015. Speeding Up Ecological and Evolutionary Computations in R; Essentials of High Performance Computing for Biologists. PLoS Comput. Biol. 11, e1004140. https://doi.org/10.1371/journal.pcbi.1004140

Visser, M.D., Wright, S.J., Muller-Landau, H. C. Jongejans, E., Comita, L.S., de Kroon, H., Schnitzer, S., 2018b. Tree species vary widely in their tolerance for liana infestation: a case study of differential host response to generalist parasites. J. Ecol. 106, 781-794.

Vrugt, J.A., Ter Braak, C.J.F., 2011. DREAM(D): An adaptive Markov Chain Monte Carlo simulation algorithm to solve discrete, noncontinuous, and combinatorial posterior parameter estimation problems. Hydrol. Earth Syst. Sci. 15, 3701-3713. https://doi.org/10.5194/hess-15-3701-2011

Waite, C.E., Heijden, G.M.F., Field, R., Boyd, D.S., 2019. A view from above: Unmanned aerial vehicles ( $<s c p>U A V</ s c p>s$ ) provide a new tool for assessing liana infestation in tropical forest canopies. J. Appl. Ecol. 56, 902-912. https://doi.org/10.1111/1365-2664.13318

Werden, L.K., Waring, B.G., Smith-Martin, C.M., Powers, J.S., 2018. Tropical dry forest trees and lianas differ in leaf economic spectrum traits but have overlapping water-use strategies. Tree Physiol. 38, 517-530. https://doi.org/10.1093/treephys/tpx135

Willard, J., Jia, X., Xu, S., Steinbach, M., Kumar, V., 2020. Integrating Scientific Knowledge with Machine Learning for Engineering and Environmental Systems 1, 1.

Wright, S.J., Sun, I.-F.I., Pickering, M., Fletcher, C.D.C., Chen, Y.-Y.Y., 2015. Long-term changes in liana loads and tree dynamics in a Malaysian forest. Ecology 96, 27482757. https://doi.org/10.1890/141985.1

Wu, J., Kobayashi, H., Stark, S.C., Meng, R., Guan, K., Tran, N.N., Gao, S., Yang, W., Restrepo-Coupe, N., Miura, T., Oliviera, R.C., Rogers, A., Dye, D.G., Nelson, B.W., Serbin, S.P., Huete, A.R., Saleska, S.R., 2018. Biological processes dominate seasonality of remotely sensed canopy greenness in an Amazon evergreen forest. New Phytol. 217, 1507-1520. https://doi.org/10.1111/nph.14939

Yang, P., van der Tol, C., Yin, T., Verhoef, W., 2020. The SPART model: A soil-plant-atmosphere radiative transfer model for satellite measurements in the solar spectrum. Remote Sens. Environ. 247, 111870. https://doi.org/10.1016/J.RSE.2020.111870

Zhang, J., Rivard, B., Sánchez-Azofeifa, A., Castro-Esau, K., 2006. Intra- and inter-class spectral variability 
bioRxiv preprint doi: https://doi.org/10.1101/2021.09.30.462145; this version posted October 1, 2021. The copyright holder for this preprint (which was not certified by peer review) is the author/funder. All rights reserved. No reuse allowed without permission.

of tropical tree species at La Selva, Costa Rica: Implications for species identification using HYDICE imagery. Remote Sens. Environ. 105, 129-141. https://doi.org/10.1016/J.RSE.2006.06.010

Zhang, Q., Xiao, X., Braswell, B., Linder, E., Baret, F., Moore, B., 2005. Estimating light absorption by chlorophyll, leaf and canopy in a deciduous broadleaf forest using MODIS data and a radiative transfer model. Remote Sens. Environ. 99, 357-371. https://doi.org/10.1016/j.rse.2005.09.009 
bioRxiv preprint doi: https://doi.org/10.1101/2021.09.30.462145; this version posted October 1, 2021. The copyright holder for this preprint (which was not certified by peer review) is the author/funder. All rights reserved. No reuse allowed without permission.

\title{
Figures and tables: Why can we dectect lianas from space?
}

\author{
immediate
}

September 30, 2021 
Spectral datasets, location and sensor information

\begin{tabular}{|c|c|c|c|c|c|c|c|c|}
\hline & Scale & $\begin{array}{l}\text { spatial } \\
\text { extent }\end{array}$ & Locations $* *$ & Year & $\begin{array}{l}\text { Species } \\
\text { (vines) }\end{array}$ & Samples & platform & Sensor \\
\hline 1 & Leaf & $<1 \mathrm{~cm}^{2}$ & Ispra, Italy & 1993 & $46(3)$ & 330 leaves & Spectroradiometer & $\begin{array}{l}\text { PerkinElmer } \\
\text { LAMBDA-19 }\end{array}$ \\
\hline 2 & & $<1 \mathrm{~cm}^{2}$ & Angers, France & 2004 & $43(5)$ & 276 leaves & Spectroradiometer & $\begin{array}{l}\text { ASD FieldSpec- } \\
\text { FR }\end{array}$ \\
\hline 3 & & $<1 \mathrm{~cm}^{2}$ & SLZ \& PNM, Panama & 2016 & 6 & 248 leaves & Spectroradiometer & SVC HR1024i \\
\hline 4 & & $<1 \mathrm{~cm}^{2}$ & SLZ \& PNM, Panama & 2017 & 28 & 852 leaves & Spectroradiometer & SVC HR1024i \\
\hline 5 & & $<1 \mathrm{~cm}^{2}$ & SLZ \& PNM, Panama & 2004 & $40(27)$ & 864 leaves & Spectroradiometer & $\begin{array}{l}\text { Unispect, PPSys- } \\
\text { tems }\end{array}$ \\
\hline 6 & & $<1 \mathrm{~cm}^{2}$ & SLZ \& PNM, Panama & 2017 & 11 & 759 leaves & Spectroradiometer & $\begin{array}{l}\text { ASD FieldSpec } \\
\text { Pro }\end{array}$ \\
\hline 7 & & $<1 \mathrm{~cm}^{2}$ & $\begin{array}{l}\text { CAM, CAR, FLMM, SB, } \\
\text { UPR, Puerto Rico }\end{array}$ & 2017 & 11 & 104 leaves & Spectroradiometer & SVC HR1024i \\
\hline 8 & & $<1 \mathrm{~cm}^{2}$ & TNF, Brazil & 2014 & 16 & 166 leaves & Spectroradiometer & $\begin{array}{l}\text { ASD FieldSpec } \\
\text { Pro }\end{array}$ \\
\hline 9 & & $<1 \mathrm{~cm}^{2}$ & DVCA, Malaysia & 2015 & 282 & $\begin{array}{l}683 \\
\text { branches }\end{array}$ & Spectroradiometer & ASD FieldSpec 4 \\
\hline 10 & & $<1 \mathrm{~cm}^{2}$ & KSFR, Malaysia & 2016 & $67(20)$ & 492 leaves & Spectroradiometer & $\begin{array}{l}\text { ASD } \text { FieldSpec } \\
\text { Pro }\end{array}$ \\
\hline 11 & Canopy & $1 \mathrm{~m}^{2}$ & DVCA, Malaysia & 2014 & NA & 455 crowns & Airborne & Asia-Fenix \\
\hline 12 & & $2 m^{2}$ & BCNM, Panama & 2012 & NA & 544 crowns & Airborne & AToMS \\
\hline 13 & Stand & $30 m^{2}$ & NER,French Guina & 2006 & NA & 450 pixels & Satellite & Landsat \\
\hline 14 & & $30 \mathrm{~m}^{2}$ & NKM, Bolivia & 2001 & NA & 8164 pixels & Satellite & Hyperion \\
\hline
\end{tabular}

Table 1: *The spectral sampling area of leaf measurements ranged between $3.46 \quad \mathrm{~mm}^{2}$ and .. ** abreviations: Parque Natural Metropolitan (PNM), Parque Nacional San Lorenzo (SLZ), Noel Kempff Mercado National Park (NKM), Cambalache State Forest (CAM), Carite State Forest (CAR), Fundacion Luis Munoz Marin (FLMM), Sabana (SB), International Institute of Tropical Forestry (UPR), Tapajos National Forest (TNF), Danum Valley Conservation Area (DVCA), Kabili-Sepilok Forest Reserve (KSFR), Barro Colorado Nature Monument (BCNM), Nouragues Ecological Research Station (NER). 
Model parameters and associated canopy and leaf traits

\begin{tabular}{|c|c|c|c|c|c|}
\hline Scale & Trait & parameter & units & Description & $\begin{array}{l}\text { Validation } \\
\text { dataset }\end{array}$ \\
\hline leaf & Leaf stuctural parameter & $\mathrm{N}$ & NA & $\begin{array}{l}\text { Average number of air-cell walls interfaces within the mesophyll. Ex- } \\
\text { pected to correlate strongly with leaf thickness. }\end{array}$ & $1,2,10$ \\
\hline leaf & $\begin{array}{l}\text { Chlorophyll A \& B content } \\
\text { per unit leaf area }\end{array}$ & $C_{a b}$ & $\mu \mathrm{gcm}^{2}$ & Primary photosynthetic pigment & 1,2 \\
\hline leaf & $\begin{array}{l}\text { Carotenoid content per unit } \\
\text { leaf area }\end{array}$ & $C_{a r}$ & $\mu \mathrm{g} / \mathrm{cm}^{2}$ & Secondary photosynthetic pigment & 1,2 \\
\hline leaf & $\begin{array}{l}\text { Water mass per unit leaf } \\
\text { area. }\end{array}$ & $C_{w}$ & $\mathrm{~g} / \mathrm{cm}^{2}$ & $\begin{array}{l}\text { Also described as "equivalent water thickness", as the parameter's } \\
\text { units reduce to } \mathrm{cm} \text { when "divided" by the density of pure water ( } 1 \\
\left.\mathrm{~g} / \mathrm{cm}^{3}\right) \text {, and then represents the hypothetical thickness of water when } \\
\text { distributed over the area of a remotely sensed pixel. }\end{array}$ & $1,2,10$ \\
\hline leaf & Leaf dry matter per area & $C_{m}$ & $\mathrm{~g} / / \mathrm{cm}^{2}$ & Oven dried weight over fresh area. & $1,2,10$ \\
\hline leaf & Anthocyanin content & $C_{a n}$ & $\mu \mathrm{g} / \mathrm{cm}^{2}$ & $\begin{array}{l}\text { Protective flavonoids protecting photostems from excess light and her- } \\
\text { bivory. }\end{array}$ & $\begin{array}{l}\text { estimated } \\
\text { (calibration } \\
\text { parameter) }\end{array}$ \\
\hline leaf & brown pigments content & $C_{b r}$ & arbitrary & Colored residu of degraded pigments during senescence of after stress. & $\begin{array}{l}\text { estimated } \\
\text { (calibration } \\
\text { parameter) }\end{array}$ \\
\hline Canopy & Leaf inclination angle & $\Omega$ & degrees & The average angular orientation of the leaf normal relative to the zenith & 16 \\
\hline Canopy & Fraction secondary particles & $f_{2}$ & unitless & $\begin{array}{l}\text { Proportion of primary (liana) leaf particles in canopy as a fraction of } \\
\text { the total LAI , with } 1-f_{2} \text { giving the fraction of primary leaves (lianas). }\end{array}$ & 15 \\
\hline Canopy & Canopy dissociation factor & $\mathrm{D}$ & unitless & $\begin{array}{l}\text { Mixing of primary (liana) and secondary (tree) particales, ranging be- } \\
\text { tween } 0 \text { and } 1 \text {, with } 0 \text { a perfectly homogeneous mixture and } 1 \text { all pri- } \\
\text { mary leaves in top layer. }\end{array}$ & fixed (set to 1$)$ \\
\hline Canopy & hotspot & $\kappa$ & unitless & $\begin{array}{l}\text { Particle coarseness, defined as the ratio of the mean (projected) particle } \\
\text { size over the width of the canopy layer (often estimated as leaf width } \\
\text { / canopy height). }\end{array}$ & fixed \\
\hline Stand & Verticle crown cover fraction & $\mathrm{Cv}$ & unitless & Percentage of ground area covered by foliage at nadir view & fixed (set to 1 ) \\
\hline Stand & Crown shape & $\zeta$ & unitless & Tree height over crown diameter & fixed \\
\hline sensor & Solar zenith angle & $\theta_{s}$ & degrees & Compliment of sun elevation in degrees from horizon (90 - elevation) & fixed \\
\hline sensor & Observer zenith angle & $\theta_{o}$ & degrees & sensors zenith angle (datasets often nadir corrected) & fixed \\
\hline sensor & $\begin{array}{l}\text { Sun-sensor relative azimuth } \\
\text { angle }\end{array}$ & $\psi$ & degrees & $\begin{array}{l}\text { Relative azimuth angle, or difference between sun and oberver azimuth } \\
\text { angles }\end{array}$ & fixed \\
\hline All & Error & $\sigma$ & unitless & residual error on predicted reflectance $\hat{\rho}$ & estimated \\
\hline
\end{tabular}

Table 2: Add caption 


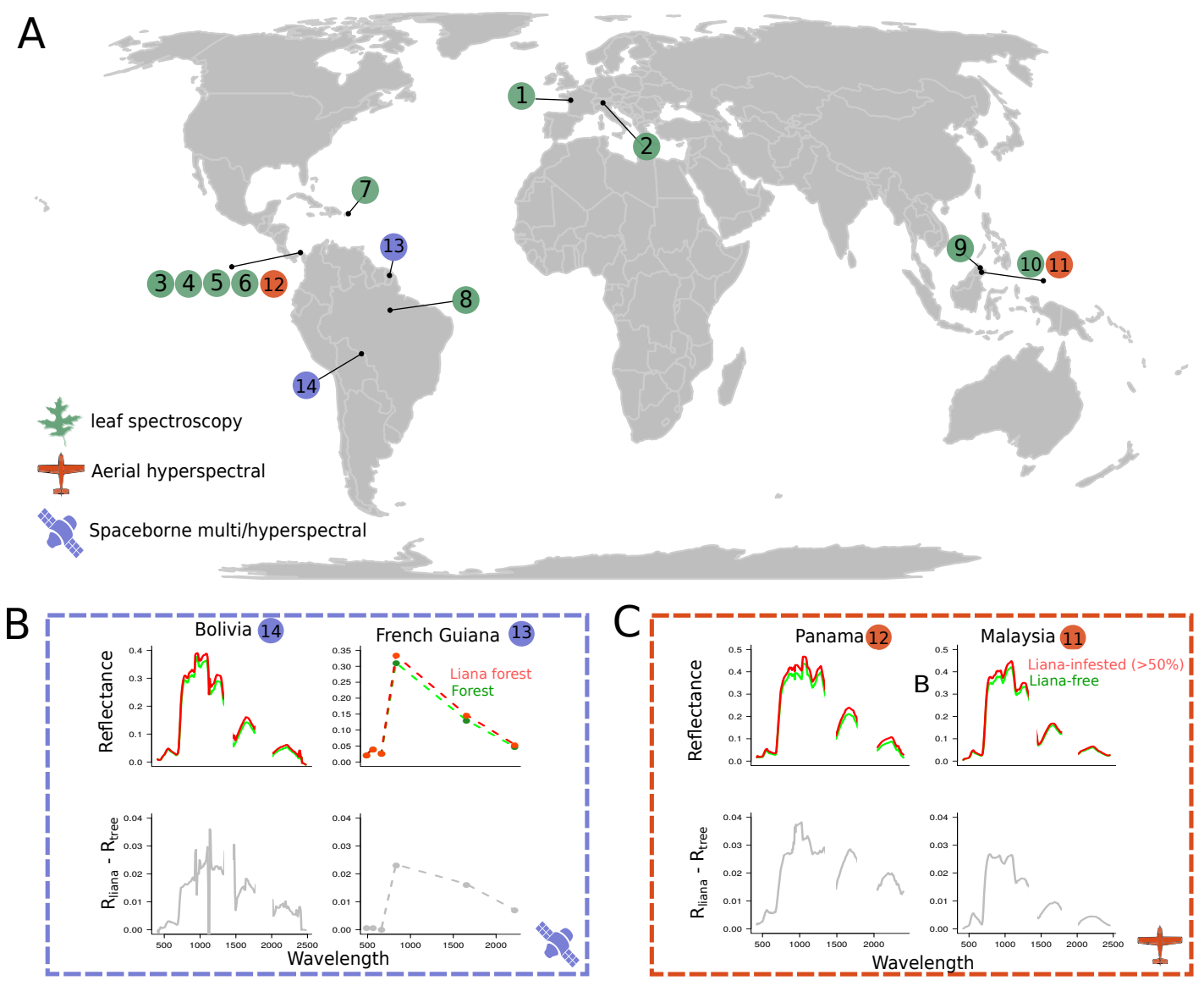

Figure 1: caption text in word document 


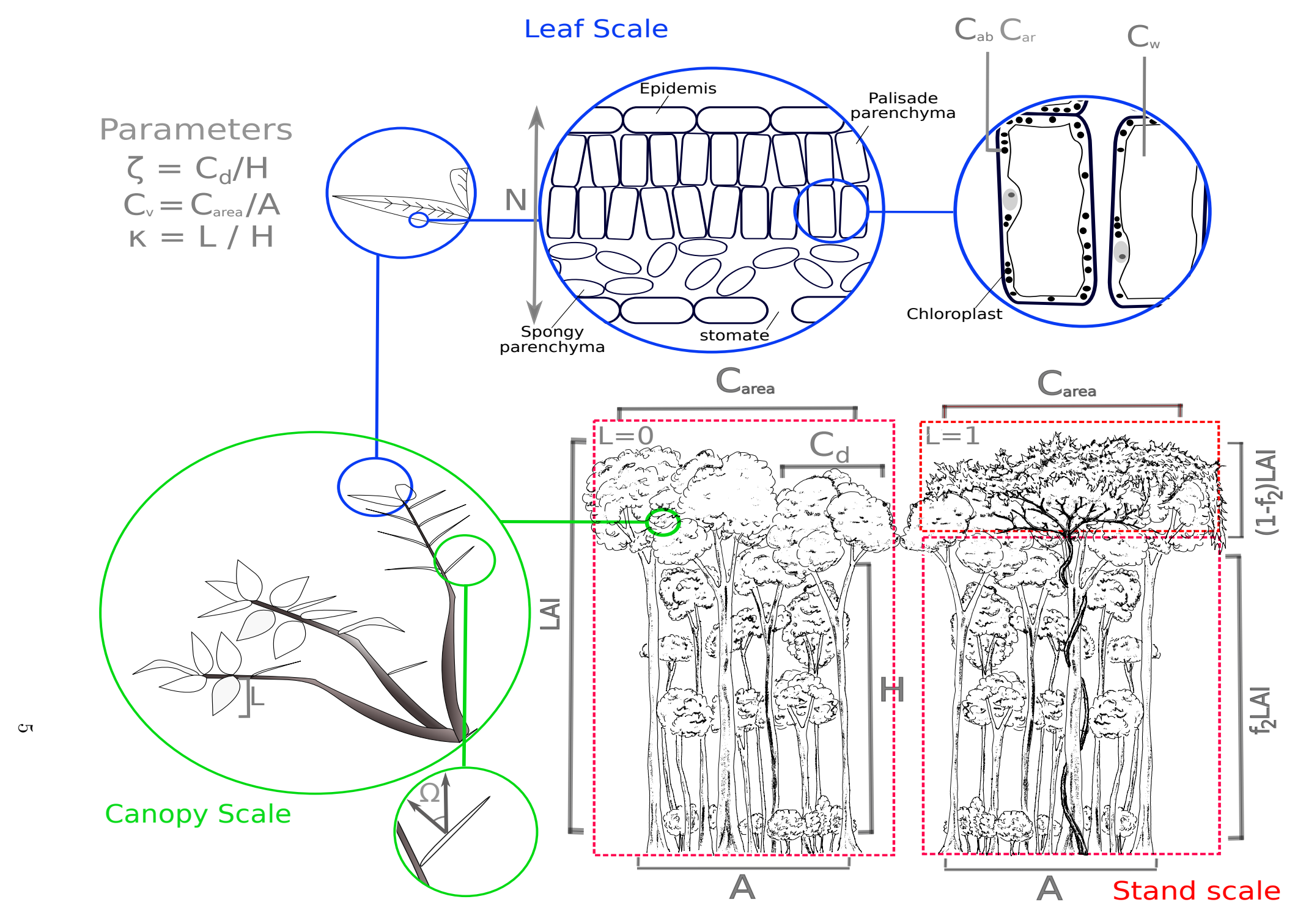

Figure 2: caption text in word document 

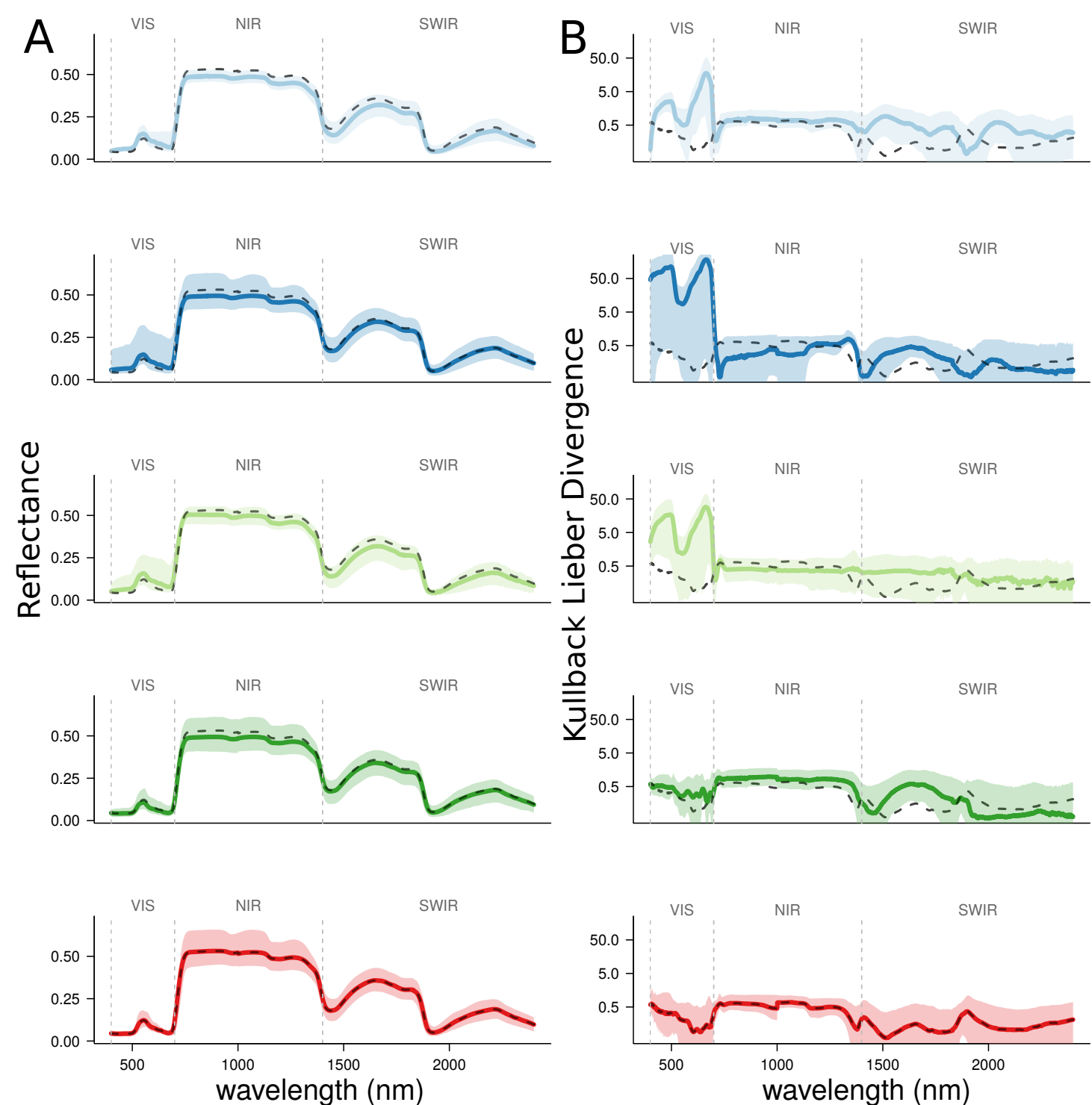
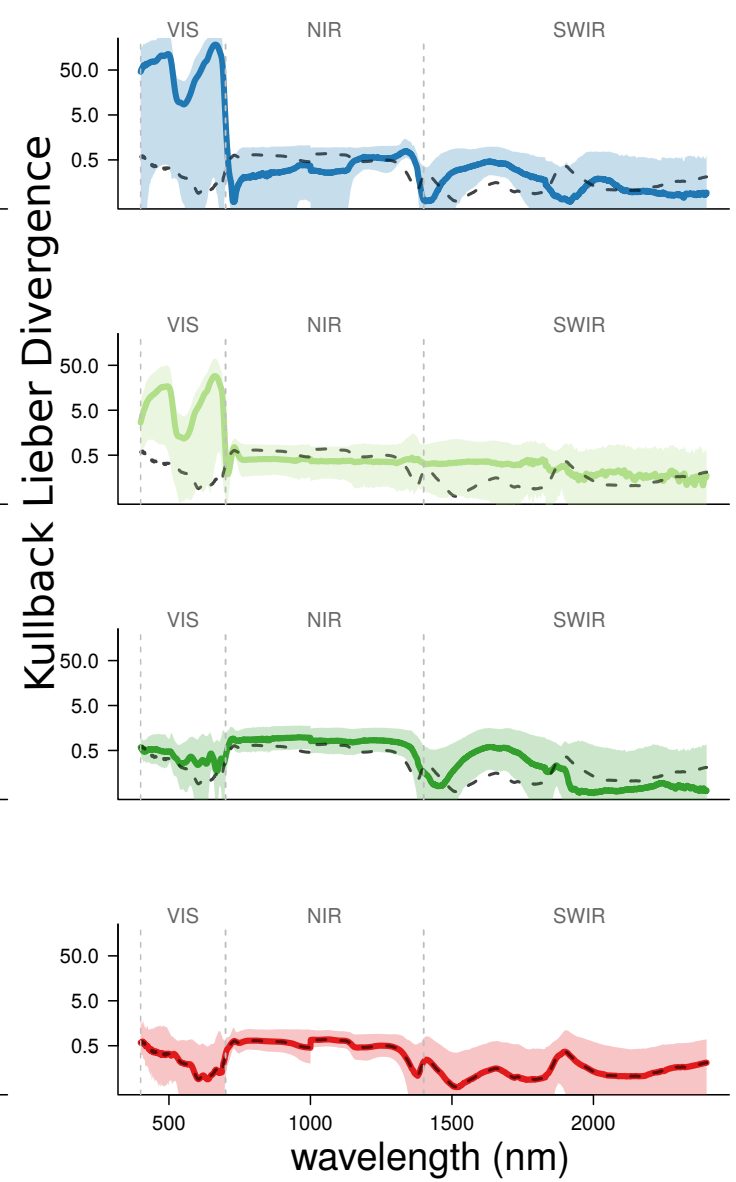

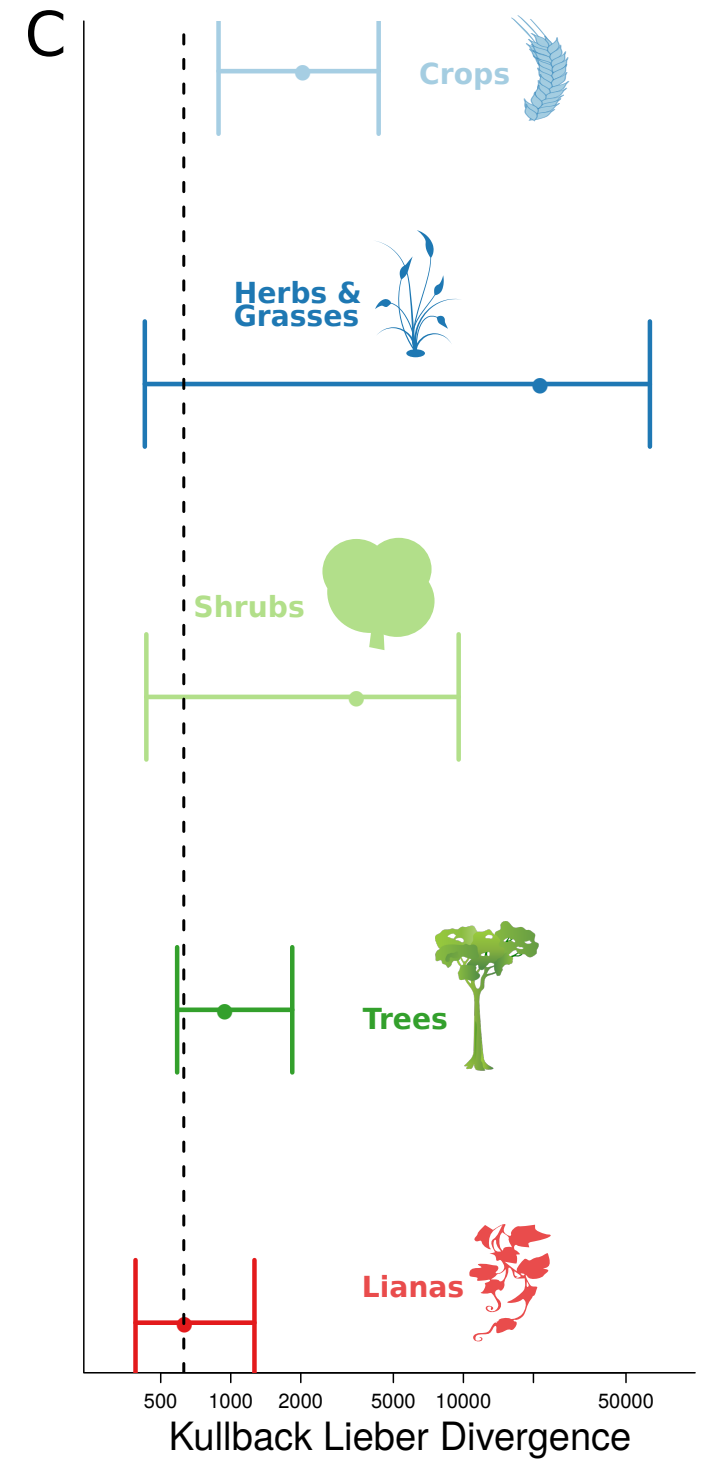

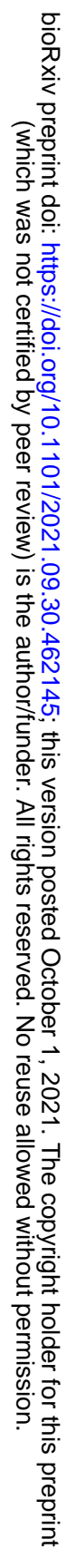

Figure 3: caption text in word document 

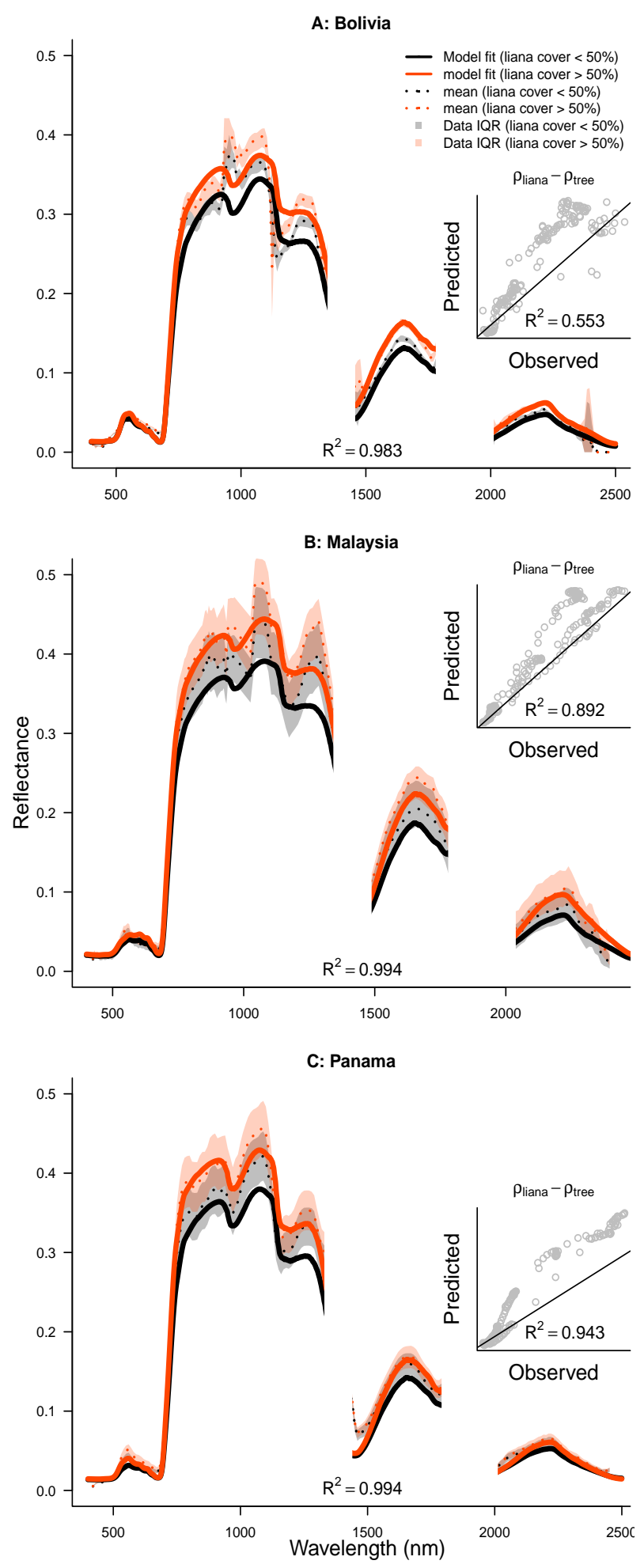

Figure 4: caption text in word document 


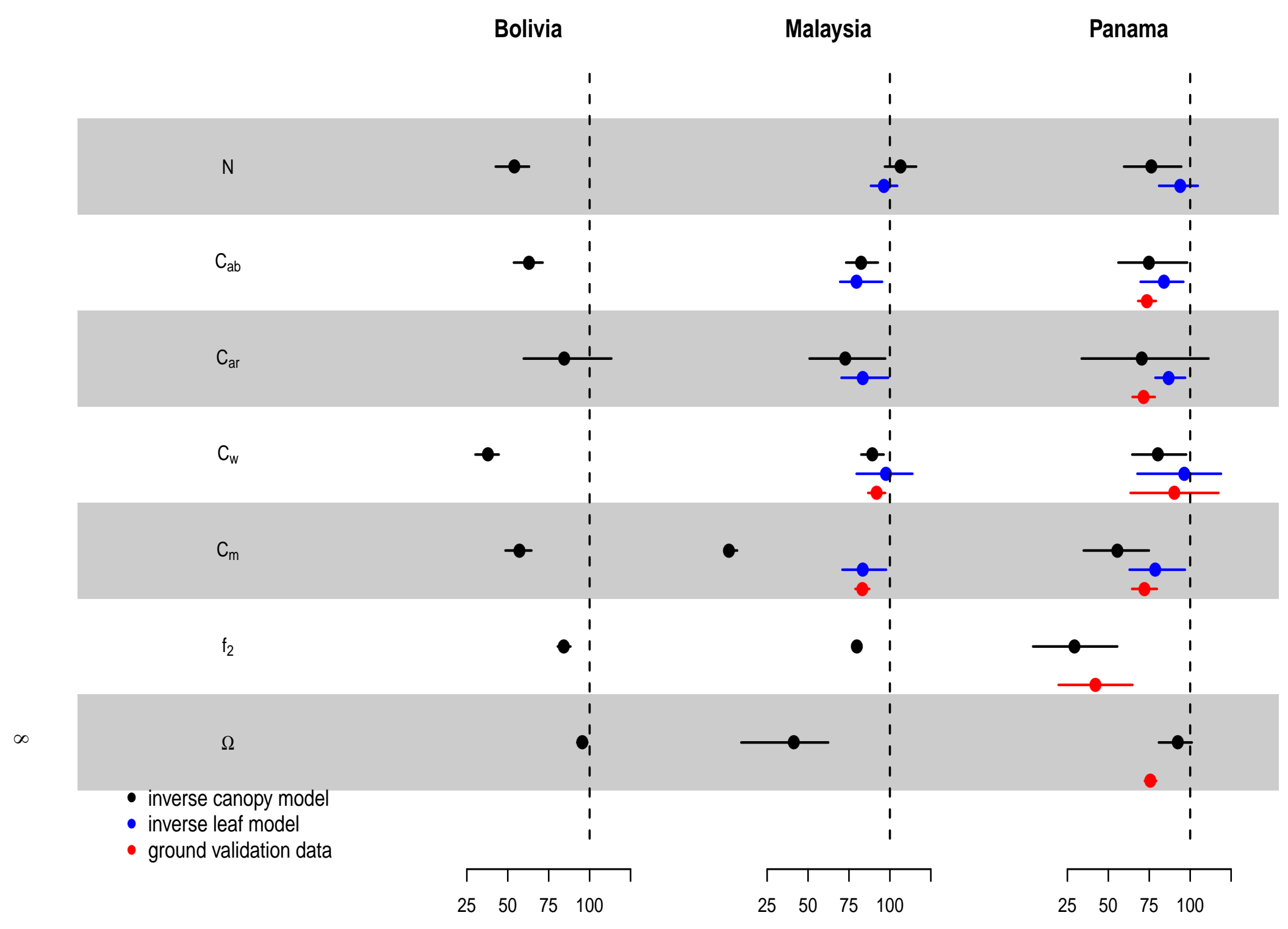

Figure 5: caption text in word document 

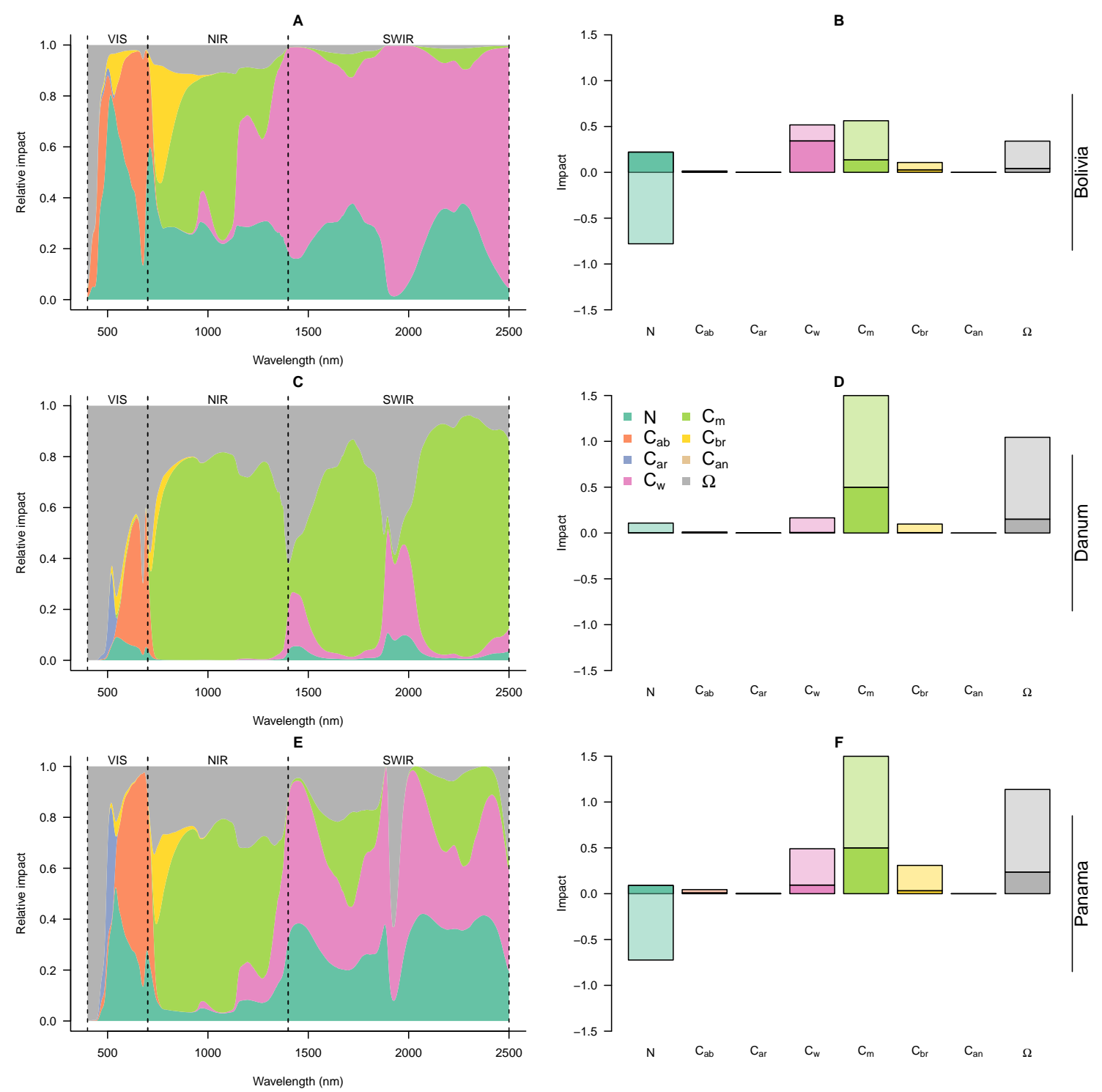

Figure 6: caption text in word document 

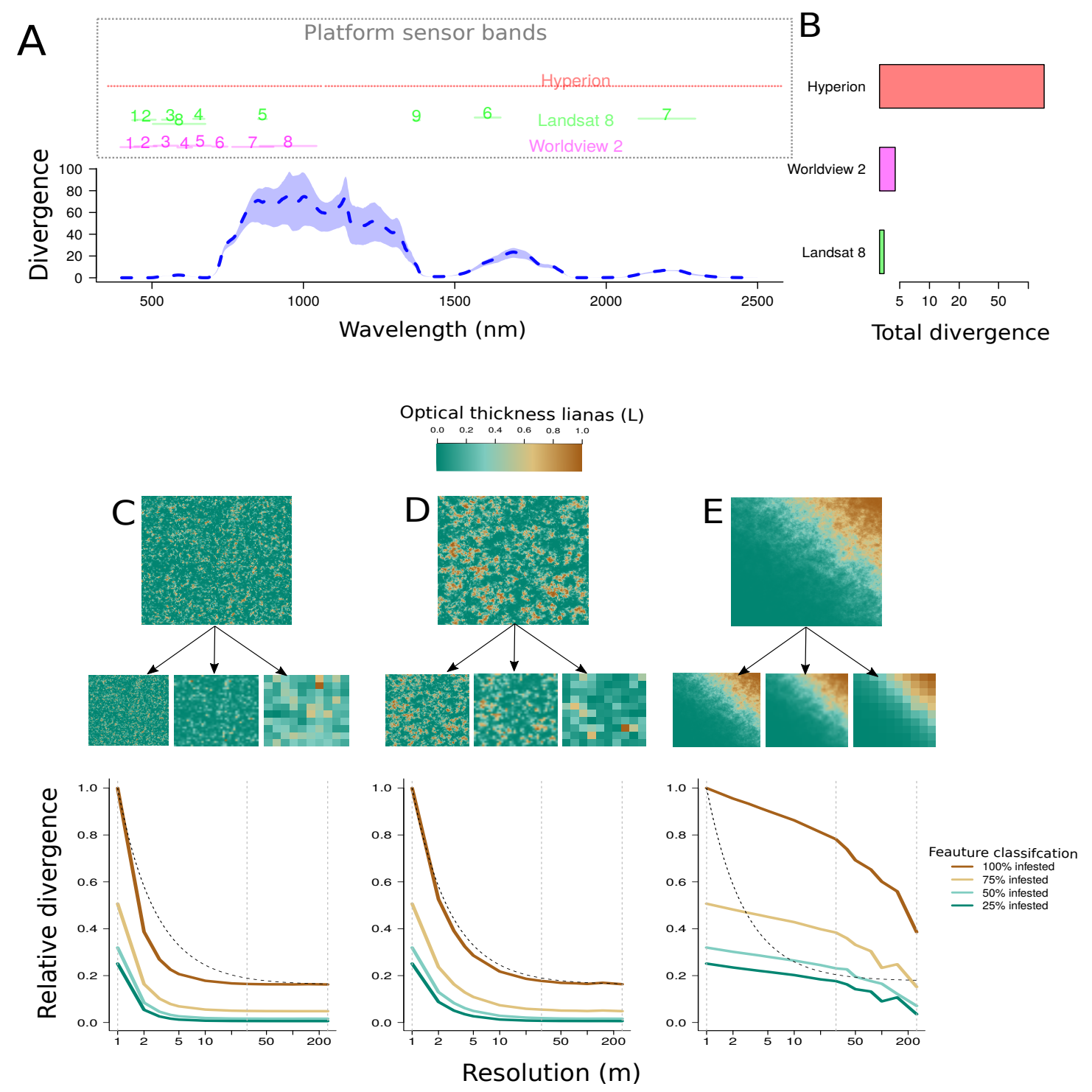

Figure 7: caption text in word document 